\title{
Synaptic activation of ribosomal protein S6 phosphorylation occurs locally in activated dendritic domains
}

\author{
Patricia Salgado Pirbhoy, ${ }^{1,2}$ Shannon Farris, ${ }^{1,3,5}$ and Oswald Steward ${ }^{1,2,3,4}$ \\ ${ }^{1}$ Reeve-Irvine Research Center; ${ }^{2}$ Department of Neurobiology and Behavior, Center for the Neurobiology of Learning and Memory; \\ ${ }^{3}$ Department of Anatomy and Neurobiology; ${ }^{4}$ Department of Neurosurgery, University of California, Irvine, California 92697, USA
}

\begin{abstract}
Previous studies have shown that induction of long-term potentiation (LTP) induces phosphorylation of ribosomal protein S6 ( $\mathrm{rpS6}$ ) in postsynaptic neurons, but the functional significance of rpS6 phosphorylation is poorly understood. Here, we show that synaptic stimulation that induces perforant path LTP triggers phosphorylation of rpS6 (p-rpS6) locally near active synapses. Using antibodies specific for phosphorylation at different sites (ser235/236 versus ser240/244), we show that strong synaptic activation led to dramatic increases in immunostaining throughout postsynaptic neurons with selectively higher staining for p-ser235/236 in the activated dendritic lamina. Following LTP induction, phosphorylation at ser235/ 236 was detectable by $5 \mathrm{~min}$, peaked at $30 \mathrm{~min}$, and was maintained for hours. Phosphorylation at both sites was completely blocked by local infusion of the NMDA receptor antagonist, APV. Despite robust induction of p-rpS6 following high frequency stimulation, assessment of protein synthesis by autoradiography revealed no detectable increases. Exploration of a novel environment led to increases in the number of p-rpS6-positive neurons throughout the forebrain in a pattern reminiscent of immediate early gene induction and many individual neurons that were p-rpS6-positive coexpressed Arc protein. Our results constrain hypotheses about the possible role of rpS6 phosphorylation in regulating postsynaptic protein synthesis during induction of synaptic plasticity.
\end{abstract}

Long-term potentiation (LTP) was first characterized in the perforant path, which is the major extrinsic input pathway from the entorhinal cortex to the dentate gyrus (Bliss and Lomo 1973; Douglas and Goddard 1975). Subsequently, it was shown that induction of perforant path LTP initiates a number of processes in postsynaptic neurons in the dentate gyrus (DG), including activation of intracellular signaling cascades (Davis et al. 2000; Chotiner et al. 2010), induction of gene transcription (Abraham and Williams 2003; Ryan et al. 2011), actin polymerization at active synapses (Fukazawa et al. 2003; Lin et al. 2005; Huang et al. 2007), and changes in synapse morphology (Fifková and Van Harreveld 1977; Desmond and Levy 1983; Harris et al. 2003; Medvedev et al. 2010).

Although LTP was first discovered in the perforant path, mechanistic studies have largely involved studies of LTP in the CA1 region of hippocampal slices in vitro. Key conclusions are that late-phase LTP in CA1 involves transcription of mRNAs (Nguyen et al. 1994; Kandel 2001) and de novo protein synthesis (Nguyen and Kandel 1996) and that some of the mRNAs critical for synaptic modification are translated locally at synapses (for review, see Steward and Schuman 2001). Elements necessary for local protein synthesis localize at synapses, including polyribosomes (Steward and Levy 1982), tRNA (Tiedge and Brosius 1996), and mRNAs (Burgin et al. 1990; Steward et al. 1998; Cajigas et al. 2012). Also, some mRNAs, including the mRNA for the immediate early gene (IEG), Arc/Arg3.1 (Link et al. 1995; Lyford et al. 1995), and CAMKII localize selectively near active synapses (Steward et al. 1998; Farris et al. 2014), supporting other evidence that the proteins encoded by these mRNAs are important for activity-dependent synaptic modifications.

5Present address: NIH/NIEHS, Research Triangle Park, NC 27709, USA.
Corresponding author: osteward@uci.edu Corresponding author: osteward@uci.edu
Article is online at http://www.learnmem.org/cgi/doi/10.1101//m.041947.116.
Despite considerable information on mRNA localization in dendrites and at activated synapses, mechanisms controlling local translation of mRNAs are relatively unexplored. One interesting lead comes from a study showing that induction of perforant path LTP in vivo triggers phosphorylation of eukaryotic initiation factor $4 \mathrm{E}$ (eIF4E) and ribosomal protein S6 and dephosphorylation of eIF2- $\alpha$ (Panja et al. 2009) in dentate granule cells. These alterations in phosphorylation state were maintained during the critical time window that stimulation-induced mRNA transcripts for the IEG, Arc, were being translated. Ribosomal protein S6 (rpS6) is of particular interest because it undergoes inducible phosphorylation in response to various stimuli (Meyuhas 2008) and is implicated in the regulation of translation initiation and protein synthesis (Thomas et al. 1982; Jefferies and Thomas 1996). RpS6 is localized near the mRNA/tRNA binding site junction between the $40 \mathrm{~S}$ and $60 \mathrm{~S}$ ribosomal subunits (Nygard and Nilsson 1990) making it a prime candidate to regulate recruitment of mRNA into polysomes (Nielsen et al. 1981).

In cells in culture, induction of rpS6 phosphorylation is associated with translation initiation of protein synthesis (Thomas et al. 1982; Jefferies and Thomas 1996) and preferential mobilization of specific mRNAs into polysomes (Duncan and McConkey 1982; Jefferies and Thomas 1996; Meyuhas 2000). Phosphorylation of rpS6 (p-rpS6) enhances translation of mRNAs containing a $5^{\prime}$-terminal tract of oligopyrimidines (5'TOP mRNAs), which encode elements of the translational machinery (Jefferies et al. 1994). Nevertheless, p-rpS6 alone is not always sufficient for

(C) 2016 Pirbhoy et al. This article is distributed exclusively by Cold Spring Harbor Laboratory Press for the first 12 months after the full-issue publication date (see http://learnmem.cshlp.org/site/misc/terms.xhtml). After 12 months, it is available under a Creative Commons License (AttributionNonCommercial 4.0 International), as described at http://creativecommons. org/licenses/by-nc/4.0/. 
activation of 5'TOP mRNA translation (Tang et al. 2001; Barth-Baus et al. 2002; Stolovich et al. 2002) and has been shown to be dispensable for the rate of protein synthesis (Kruppa and Clemens 1984; Mieulet et al. 2007). Thus, the significance of synaptically induced p-rpS6 on mRNA translation remains to be defined.

Although Panja et al showed activity-dependent induction of p-rpS6, little is known, about the subcellular location within postsynaptic neurons where changes in phosphorylation occur, especially whether they occur near activated synapses. We explored this question here using phospho-specific antibodies for different phosphorylation sites on rpS6 (ser235/236 and ser240/244). We show that high frequency activation of the perforant path triggers robust induction of p-rpS6 in dentate granule cells with stronger induction of p-ser235/236 in the portion of the dendrite contacted by activated synapses. We further show that synaptically driven induction of p-rpS6 is NMDA receptor-dependent, and persists for hours after LTP induction. Moreover, a learning experience (exploration of a novel environment) also triggers p-rpS6 in individual neurons in a particular pattern similar to that of IEG induction. Surprisingly, the striking increases in p-rpS6 following high-frequency stimulation were not accompanied by detectable increases in postsynaptic protein synthesis. Taken together, our results provide new insights into how rpS6 phosphorylation is regulated by synaptic activity and during learning and suggest the need for a reassessment of how synaptic activity regulates postsynaptic protein synthesis during the consolidation phase of LTP.

\section{Results}

High-frequency activation of the perforant path triggers rapid and robust phosphorylation of ribosomal protein S6 in activated dendritic laminae

We discovered the selective phosphorylation of rpS6 (p-rpS6) in the activated dendritic lamina as a result of immunostaining sections from rats in which repeated HFS was delivered to induce targeting of $A r c$ mRNA to active synapses (eight pulses at $400 \mathrm{~Hz}$ at 1 / $10 \mathrm{sec}$ for $60 \mathrm{~min}$ ). Sections from these cases were immunostained using phospho-specific antibodies for p-rpS6 at ser235/236 and ser240/244 (Fig. 1). One hour of continuous HFS resulted in robust immunostaining throughout the cell body and dendritic lamina (Fig. 1A). Most strikingly, there was a distinct band of increased immunostaining in the middle molecular layer (MML) in exactly the part of the dendritic lamina contacted by medial perforant path synapses (Fig. 1C). On the side contralateral to the stimulation, which serves as an internal control, overall levels of immunostaining for p-ser235/236 were low (Fig. 1B), although some individual granule cells exhibited high levels of immunostaining (more on this below). To quantify changes in immunostaining for p-rpS6, we measured optical density (OD) across the granule cell layer (GCL) and molecular layer ipsilateral and contralateral to the stimulation. Figure 1D plots the average OD along the dorsal blade of the dentate gyrus (DG) from GCL to outer molecular layer (OML) for the high-magnification image illustrated in Figure $1 \mathrm{C}$ and the corresponding contralateral side. The band of increased labeling in the zone of activated synapses (middle molecular layer) is evident.

It should be noted that immunostaining for $\mathrm{p}$-rpS6 varies in a way much like IEG expression in that patterns of activation depend on the animal's behavior in the period prior to death. When awake behaving animals are euthanized and prepared for p-rpS6 immunostaining, some individual neurons scattered throughout the brain are p-rpS6 positive, and the number of p-rpS6 neurons increases if the animals are exposed to a novel environment (see below). When animals have been anesthetized for

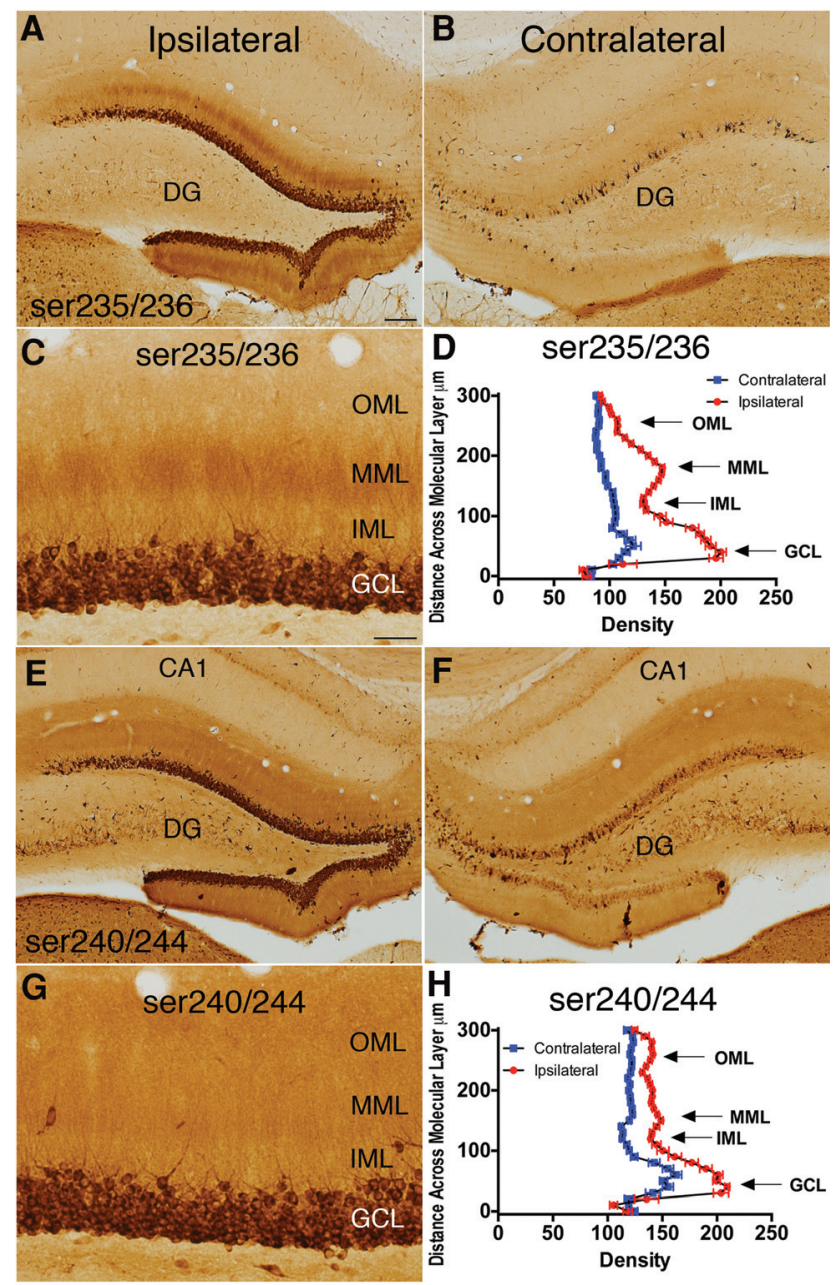

Figure 1. Unilateral HFS of the MPP triggers rapid and robust immunostaining of rpS6 phosphorylation. (A) Immunostaining of p-ser235/236 in a section ipsilateral to MPP stimulation following 60 min of HFS. (B) Immunostaining of p-ser235/236 contralateral (nonstimulated) to the stimulation. (C) High-magnification image of $A$. Note the prominent band of rpS6 phosphorylation precisely in the middle molecular layer, the layer that is selectively activated with stimulation. (D) Quantification of average OD across the dorsal blade of the dentate gyrus in both ipsilateral and contralateral sections for p-ser235/236. (E) Immunostaining of p-ser240/244 in a section ipsilateral to MPP stimulation following $60 \mathrm{~min}$ of HFS. $(F)$ Immunostaining of p-ser240/244 contralateral to the stimulation. $(G)$ High-magnification image of $E$. Note that p-ser240/244 immunostaining has higher basal levels of immunostaining throughout the granule and dendritic layers of the dentate gyrus. $(H)$ Quantification of average $O D$ across the dorsal blade of the dentate gyrus in both ipsilateral and contralateral sections for p-ser240/244. DG, dentate gyrus; GCL, granule cell layer; IML, inner molecular layer; $\mathrm{MML}$, middle molecular layer; OML, outer molecular layer. Scale bars: A, $200 \mu \mathrm{m} ; \mathrm{C}, 50 \mu \mathrm{m}$.

an hour or more, overall levels of immunostaining are lower than for brains collected without prolonged anesthesia. In this regard, the pattern of immunostaining on the contralateral (nonstimulated) side in Figure 1B is noteworthy because of the number of p-rpS6-positive dentate granule cells. This is a relatively rostral section, and it should be noted that there is a sparse crossed projection from the entorhinal cortex of one side to the rostral dentate gyrus on the contralateral side which does activate dentate granule neurons (Levy and Steward 1979). It is possible that immunostaining of granule cells evident in Figure $1 \mathrm{~B}$ reflects activation by the crossed pathway. 
The pattern of immunostaining for p-ser240/244 was different than that observed for p-ser235/236 on both the stimulated and control (nonstimulated) sides (Fig. 1E,F). On the stimulated side (Fig. 1E), there was intense immunostaining of the majority of granule cell bodies and increased staining throughout the dendritic lamina. Although discernable, the band of increased immunostaining for p-rpS6 in the MML was less pronounced for $p$-ser240/244 than for $p$-ser235/236. Instead of a distinct band, quantitative assessment of the average OD over the dorsal blade of the dentate gyrus revealed a general increase in immunostaining for p-ser240/244 throughout the dendritic lamina (Fig. $1 \mathrm{H})$. On the nonstimulated side (Fig. $1 \mathrm{~F})$, basal levels of immunostaining in the molecular layer of the dentate gyrus were higher for p-ser240/244 than for p-ser235/236 (Fig. 1B) in the cell bodies and dendritic layers.

\section{The extent of rpS6 phosphorylation induction depends on the duration of high frequency stimulation}

Figure 1 illustrates activation of p-rpS6 with prolonged HFS, but for physiological relevance, it is important to determine how much synaptic activation is required to induce phosphorylation of rpS6. To define the stimulation conditions required to induce maximal p-rpS6, short high frequency trains (10 pulses at $400 \mathrm{~Hz}$ ) were delivered at an interval of one-train/10 sec for 5,15 , 30,60 , or $120 \mathrm{~min}$ to generate a stimulus dose-rpS6 phosphorylation response curve. Delivery of merely 30 high frequency trains (5 min of HFS) led to increases in immunostaining for $\mathrm{p}$ ser235/236 in granule cell bodies and dendritic laminae (Fig. 2B). Quantification of OD for immunostaining of p-rpS6 at ser235/236 at two measuring sites across the dorsal blade of the dentate gyrus, GCL and MML, revealed that increases were evident at $5 \mathrm{~min}$ and became more prominent with longer periods of stimulation (Fig. $2 \mathrm{M}, \mathrm{N}$, respectively). Comparison of levels of immunostaining on the stimulated versus control sides with different durations of HFS ( $N=5$ animals per time point) by two-way ANOVA yielded an overall $F_{(4,40)}=7.45, \quad P=0.0001$ in the GCL and an overall $F_{(4,40)}=9.85, P<0.0001$

in the MML. Post hoc analysis with Bonferroni correction revealed significant differences between stimulated and control sides at alltime points for both the GCL and MML for ser235/236 (Fig. 2M,N, respectively, for details on statistics, see figure legends).

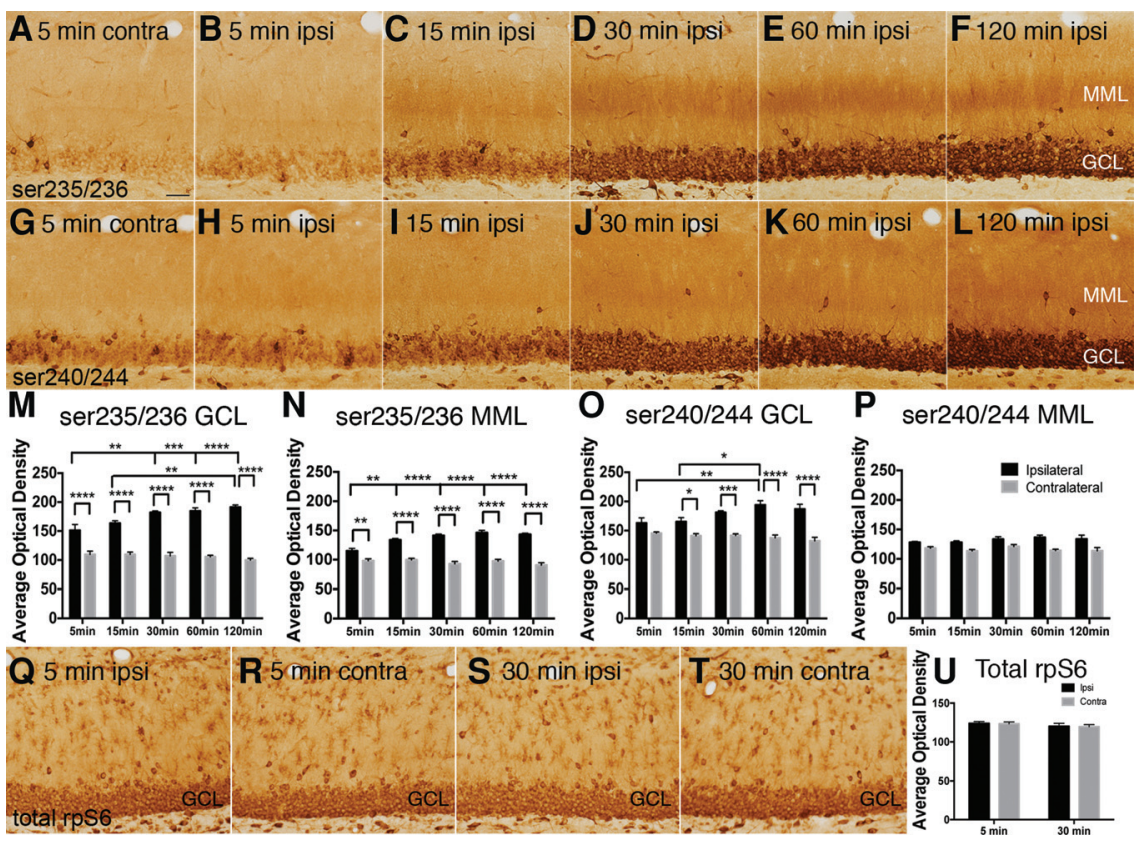

Figure 2. Stimulus dose-rpS6 phosphorylation time course reveals extent of p-rpS6 depends on duration of HFS. (A) Immunostaining of p-ser235/236 contralateral to stimulation following 5 min (30 trains) of HFS. (B) Immunostaining of p-ser235/236 ipsilateral to stimulation following 5 min (30 trains) of HFS. (C $-F)$ Immunostaining of p-ser235/236 ipsilateral to stimulation following 15, 30, 60, and 120 min of continuous HFS, respectively. (G) Immunostaining of p-ser240/244 contralateral to stimulation following $5 \mathrm{~min}$ (30 trains) of HFS. (H) Immunostaining of p-ser240/244 ipsilateral to stimulation following 5 min (30 trains) of HFS. ( $I-L)$ Immunostaining of p-ser240/244 ipsilateral to stimulation following 15, 30, 60, and 120 min of continuous HFS, respectively. (M) Quantification of average OD of p-ser $235 / 236$ across the dorsal blade of the dentate gyrus in ipsilateral and contralateral sections for each time point along the granule cell layer $(\mathrm{GCL})$. Statistical assessment by two-way ANOVA revealed a significant interaction $\left(F_{(4,40)}=7.45, P=0.0001\right)$, main effect of condition $\left(F_{(1,40)}=\right.$ 429.84, $P<0.0001)$ and main effect of time $\left(F_{(4,40)}=3.32, P=0.0194\right)$. Post hoc analysis with Bonferroni's correction revealed significant differences between ipsilateral and contralateral $O D$ at all-time points in the GCL (two-way ANOVA, $P<0.05, N=5$ per time point). Post hoc analysis also revealed a significant difference between 5 min ipsilateral versus 30,60, and $120 \mathrm{~min}$ ipsilateral OD and 15 min ipsilateral versus 120 min ipsilateral $\mathrm{OD}(P<0.05, N=5)$. $(N)$ Quantification of average OD of p-ser235/236 in the middle molecular layer (MML) of the DG in ipsilateral and contralateral sections for each time point. Statistical assessment by two-way ANOVA revealed a significant interaction $\left(F_{(4,40)}=\right.$ $9.85, P<0.0001)$, a significant main effect of condition $\left(F_{(1,40)}=357.91, P<0.0001\right)$, and significant main effect of time $\left(F_{(4,40)}=5.65, P=0.0011\right)$. Post hoc analysis with Bonferroni's correction revealed significant differences between ipsilateral and contralateral average OD at all-time points (two-way ANOVA, $P<0.05, N=5$ ). Post hoc analysis also revealed a significant difference between 5 min ipsilateral versus $15,30,60$, and $120 \mathrm{~min}$ ipsilateral OD $(P<0.05)$. (O) Quantification of average OD of p-ser240/244 in the GCL. Statistical assessment by two-way ANOVA revealed a significant interaction $\left(F_{(4,40)}=4.54, P=0.0041\right)$, a significant main effect of condition $\left(F_{(1,40)}=109.78, P<0.0001\right)$, but no main effect of time $\left(F_{(4,40)}=1.62, P=0.1893\right)$. Post hoc analysis with Bonferroni's correction revealed a significant difference between ipsilateral and contralateral OD at all-time points in the GCL except for the 5-min time point (two-way ANOVA, $P<0.05, N=5$ ). Post hoc analysis also revealed a significant difference between the $5 \mathrm{~min}$ ipsilateral versus $60 \mathrm{~min}$ ipsilateral $O D$ and $15 \mathrm{~min}$ ipsilateral versus 60 min ipsilateral OD (two-way ANOVA, $P<0.05, N=5$ ) in the GCL. (P) Quantification of average OD of $p$-ser240/244 in MML for ipsilateral and contralateral sections. Statistical assessment by two-way ANOVA revealed a significant main effect of condition $\left(F_{(1,40)}=41.97, P<0.0001\right)$ but no main effect of time $\left(F_{(4,40)}=0.5014, P=0.5014\right)$ or interaction $\left(F_{(4,40)}=0.96, P=0.4394\right)$. (Q) Immunostaining for total rpS6 in section ipsilateral to stimulation following 5 min (30 trains) of HFS. (R) Immunostaining for total $\mathrm{rpS} 6$ contralateral to stimulation following (30 trains) of HFS. (S) Immunostaining for total rpS6 ipsilateral to stimulation following $30 \mathrm{~min}$ of continuous HFS. (T) Immunostaining for total rpS6 contralateral to stimulation following $30 \mathrm{~min}$ of continuous HFS. (U) Quantification of average OD of rpS6 for ipsilateral and contralateral sections following 5 and 30 min of HFS (main effect of condition: $F_{(1,16)}=0.04, P=0.8451$; main effect of time: $F_{(1,16)}=1.73, P=$ $0.2074)$; interaction: $F_{(1,16)}=0.00, P=0.9870$, one-way ANOVA). $G C L$, granule cell layer; $M M L$, middle molecular layer. Scale bar: A, $50 \mu \mathrm{m}$. Error bars are SEM.

There were also increases in immunostaining for p-ser240/ 244 after 5 min of HFS (Fig. 2H) over both cell bodies and dendrites. Quantification of OD of immunostaining for p-ser240/ 244 at the two measuring sites, GCL and MML, revealed that the 
extent of the increase in staining in the dendritic layer was not as great as that observed for $\mathrm{p}$-ser235/236 but became more prominent with longer periods of stimulation (Fig. 2O,P, respectively). Comparisons of levels of immunostaining on the stimulated versus control sides with different durations of HFS $(N=5$ animals per time point) by two-way ANOVA yielded an overall $F_{(4,40)}=$ $4.54, P=0.0041$ in the GCL and an overall $F_{(4,40)}=0.96, P=$ 0.4394 in the MML. Post hoc analysis with Bonferroni correction revealed significant differences between stimulated and control sides at all-time points for the granule cell layer for p-ser240/ 244 except for the 5-min time point (Fig. 2O,P, for statistics, see figure legend). Although the band of increased immunostaining in the activated dendritic lamina was detected for p-ser240/244, the band was not as prominent as that observed with immunostaining for $\mathrm{p}$-ser235/236. In the MML, the average percent change from contralateral following 30-120 min of HFS for p-ser235/236 was $45.6 \%$ versus $7.5 \%$ for p-ser $240 / 244$ (two-way ANOVA, $F_{(4,40)}=3.23, P=0.0218, N=5$ ). Post hoc analysis with Bonferroni correction revealed significant differences between p-ser235/236 and p-ser240/244 at all-time points except the 5-min time point $(P<0.05)$.

To determine whether the robust phosphorylation of $\mathrm{rpS} 6$ observed with prolonged HFS is also accompanied with an increase in the synthesis of rpS6, immunostaining for total rpS6 was done to quantify the changes in the synthesis of rpS6. Immunostaining for total rpS6 revealed no difference between stimulated and nonstimulated (control) sides following 5-120 min of continuous HFS. Figure $2 \mathrm{Q}-\mathrm{T}$, shows representative images of stimulated and nonstimulated sides following 5 and $30 \mathrm{~min}$ of continuous HFS. Comparisons of levels of immunostaining on the stimulated versus control sides following 5 and 30 min of continuous HFS ( $N=5$ animals per time point) by two-way ANOVA yielded an overall $F_{(1,16)}=0.00, P=0.9870$ (Fig. 2U).

\section{Rapid and prolonged phosphorylation of ribosomal protein S6 following induction of long-term potentiation} Determining when rpS6 phosphorylation initiates, peaks, and depletes sets constraints on which mRNAs may be preferentially translated after a bout of synaptic activity, for example, as a result of induction of LTP. For instance, newly synthesized Arc mRNA does not reach dendrites in quantity until $\sim 30$ min after transcription is induced (Wallace et al. 1998). Phosphorylation of rpS6 could affect translation of newly synthesized Arc in dendrites only if activation in dendrites persists until the mRNAs are available for translation. To determine the duration of p-rpS6 post-LTP induction, we induced LTP in anesthetized rats (30 trains at $400 \mathrm{~Hz}, 1 / 10 \mathrm{sec}$ ) and allowed rats to survive for periods ranging from $5 \mathrm{~min}$ to $6 \mathrm{~h}$ post-LTP induction. Immunostaining for p-ser235/236 and p-ser240/244 of rpS6 revealed similar activation parameters but overall increases in immunostaining for p-ser235/ 236 were more robust than for p-ser240/244 (Fig. 3A-J versus Fig. $3 \mathrm{~K}-\mathrm{T}$, respectively).

Increases in immunostaining for p-ser235/236 were first evident in the granule cell layer and dendrites $15 \mathrm{~min}$ poststimulation (Fig. 3C) and peak phosphorylation was observed at $30 \mathrm{~min}$ (Fig. 3D). Levels of p-rpS6 remained enhanced $4 \mathrm{~h}$ post-LTP and returned to baseline levels $6 \mathrm{~h}$ post-LTP induction (Fig. 3I). Similarly, for p-ser240/244, initial increases in immunostaining in both the GCL and MML were first evident 15 min poststimulation (Fig. 3M) and peak phosphorylation was observed at $30 \mathrm{~min}$ (Fig. 3N). Levels of p-rpS6 began to decrease $4 \mathrm{~h}$ post-LTP and returned to baseline levels $6 \mathrm{~h}$ post-LTP induction (Fig. 3S).

To quantitate the changes in p-rpS6 over time, we assessed relative OD in the GCL and MML ipsilateral and contralateral to the stimulation, determined the ratio of ipsilateral to contralateral (I/C) signal, and then expressed values as percent change from contralateral, which provides an internal control for any variability in immunostaining across sections. Figure 3E and J illustrate a plot of the changes in immunostaining over time post-LTP induction over the GCL and the MML for p-ser235/236. A one-way ANOVA comparing percent change in OD in the GCL revealed an overall $F_{(6,28)}=2.785, P=0.0299$ in the GCL and an overall $F_{(6,28)}=7.972, P<0.0001$ in the MML $(N=5$ for each time point). Figure $3 \mathrm{O}$ and $\mathrm{T}$ illustrate a plot of the changes in immunostaining over time post-LTP induction over the GCL and the MML for p-ser240/244. A one-way ANOVA comparing the percent change in OD in the GCL revealed an overall $F_{(6,28)}=3.264, P=$ 0.0146 and an overall $F_{(6,28)}=4.078, P=0.0046$ in the MML ( $N=5$ for each time point). For statistical comparisons between individual time points, see figure legend. These quantitative results reveal that p-rpS6 after brief HFS to induce LTP actually peaks at a time when newly transcribed Arc mRNA transcripts are appearing in dendrites.

It was noteworthy that even when HFS was delivered for $2 \mathrm{~h}$, astrocytes in the activated zone did not stain positively for p-rpS6. P-rpS6-positive astrocytes were seen only near electrode tracks. This is noteworthy because of the striking activation of p-rpS6 in astrocytes by a learning experience (see below).

\section{Phosphorylation of rpS6 is dependent on NMDA receptor activation}

Because LTP induction requires activation of postsynaptic NMDA receptors (Gustafsson and Wigström 1988), we assessed whether the NMDA receptor antagonist, APV, blocked activation of rpS6 phosphorylation. For this, a micropipette containing APV (10 $\mathrm{mg} / \mathrm{mL}$ in saline) was positioned in the dorsal blade of the dentate gyrus prior to HFS and baseline responses were collected for $10 \mathrm{~min}$ followed by delivery of continuous HFS (60 min). Immediately after stimulation, each animal was perfused and brain sections were immunostained for p-rpS6 as above.

We have previously shown that when APV-filled micropipettes are positioned in the dentate gyrus prior to HFS, IEG induction is blocked in an area several millimeters in diameter around the micropipette (Steward and Worley 2001). Blockade is local, so areas distant from the APV-filled micropipette serve as an intraanimal control. APV also blocks LTP of population excitatory postsynaptic potentials (EPSPs) and population spikes recorded from the infusion area, providing an on-line positive control for the effectiveness of NMDA-receptor blockade.

In the presence of APV, there was no increase in population EPSP slope or population spike amplitude following delivery of 30 high frequency trains (our standard paradigm for inducing perforant path LTP). The percent change from baseline recorded via the APV micropipette was $-6.13 \% \pm 15.12 \%$ for population spike amplitude in comparison to $114.15 \% \pm 17.99 \%$ in control experiments with saline-filled microelectrodes. The percent change from drug baseline for population EPSP slope was 4.49\% $\pm 11.24 \%$ in comparison to $30.25 \% \pm 2.22 \%$ in control experiments.

Immunostaining for $\mathrm{p}$-ser235/236 revealed strong activation of p-rpS6 in areas distant from the APV-filled micropipette (Fig. $4 \mathrm{~A}, \mathrm{~B})$ and a complete block of p-rpS6 in the area of APV infusion (Fig. 4E,F). Within the infusion area, immunostaining was comparable to the contralateral control (Fig. 4G,H). Higher magnification views (Fig. 4F) reveal a few individual neurons that are positive for p-rpS6 as on the control side (Fig. $4 \mathrm{H}$ ).

Similarly, immunostaining for p-ser240/244 revealed strong activation of p-rpS6 in areas distant from the APV-filled micropipette (Fig. 4I,J), whereas immunostaining in the area of APV infusion (Fig. $4 \mathrm{M}, \mathrm{N}$ ) was comparable to that on the contralateral 

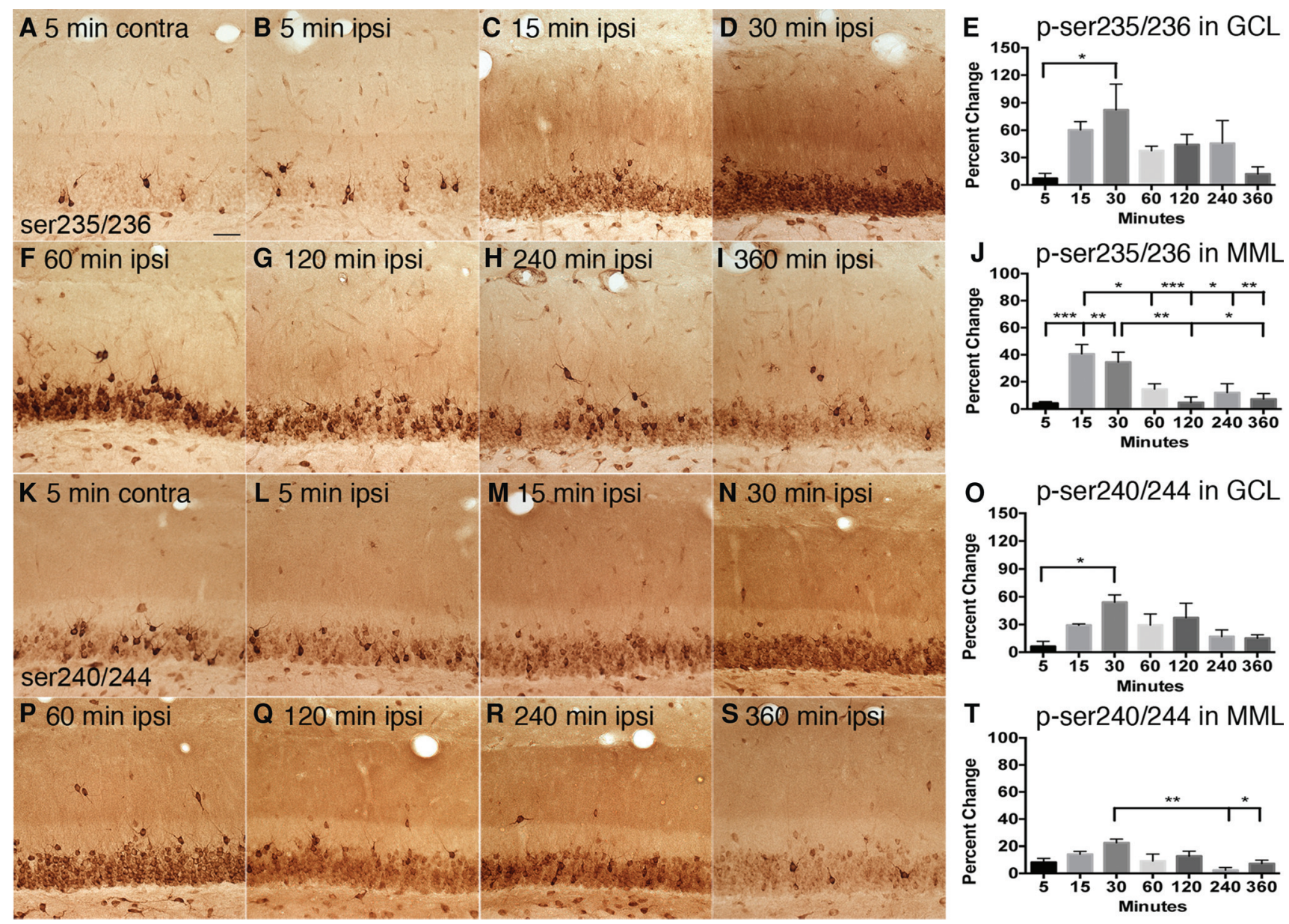

Figure 3. LTP induction triggers rapid and prolonged phosphorylation of rpS6. (A) Immunostaining of p-ser $235 / 236$ contralateral to stimulation 5 min (10 trains) post-HFS delivery. (B) Immunostaining of p-ser235/236 ipsilateral to stimulation $5 \mathrm{~min}$ (10 trains) post-HFS delivery. (C-H) Immunostaining of p-ser235/236 ipsilateral to stimulation at a time point 15, 30, 60,120, 240, and 360 min post-LTP induction (30 trains), respectively. (I) Quantification of percent change from contralateral for p-ser235/236 in the GCL of the dorsal blade of the DG. Statistical assessment by one-way ANOVA revealed an overall $F_{(6,28)}=2.785, P=0.0299$. Post hoc analysis with Bonferroni's correction revealed a significant difference in percent change between 5 and 30 min post-LTP. (J) Quantification of percent change from contralateral for $p$-ser235/236 in the MML of the dorsal blade of the DG. Statistical assessment by one-way ANOVA revealed an overall $F_{(6,28)}=7.972, P<0.001$. Post hoc analysis with Bonferroni's correction revealed a significant difference in percent change between 5 versus $15,30 \mathrm{~min}, 15$ versus $60,120,240,360 \mathrm{~min}$, and 30 versus 120,360 min post-LTP. (K) Immunostaining of p-ser240/244 contralateral to stimulation 5 min (10 trains) post-HFS delivery. (L) Immunostaining of p-ser240/244 ipsilateral to stimulation 5 min (10 trains) post-HFS delivery. $(M-R)$ Immunostaining of p-ser240/244 ipsilateral to stimulation at a time point 15, 30, 60,120, 240, and 360 min post-LTP induction (30 trains), respectively. (S) Quantification of percent change from contralateral for p-ser240/244 in the GCL of the dorsal blade of the DG. Statistical assessment by one-way ANOVA revealed an overall $F_{(6,28)}=3.264, P=0.0146$. Post hoc analysis with Bonferroni's correction revealed a significant difference in percent change between 5 and 30 min post-LTP. ( $T$ ) Quantification of percent change from contralateral for p-ser240/244 in the MML of the dorsal blade of the DG. Statistical assessment by one-way ANOVA revealed an overall $F_{(6,28)}=4.078, P=0.0046$. Post hoc analysis with Bonferroni's correction revealed a significant difference in percent change between 30 versus 240, and 360 min post-LTP. Scale bars: A, $50 \mu \mathrm{m}$. Error bars are S.E.M.

nonstimulated side (Fig. 4O,P). Quantitative analyses as above revealed that in the area surrounding the micropipette, levels of immunostaining for both p-ser235/236 and p-ser240/244 were actually somewhat less than on the contralateral (control) values (Fig. 4C,K, respectively, see legends for statistics). These data indicate that NMDA receptor activation is critical for activation of rpS6 phosphorylation in both cell body and dendritic layers.

\section{Exploration of a novel environment leads to increased numbers of p-rpS6-positive neurons}

Learning experiences activate some of the same intracellular cascades as seen with induction of LTP, including activation of IEG expression in select populations of neurons. To further explore linkages between regulation of rpS6 phosphorylation and learning, we assessed rpS6 phosphorylation following exploration of a toy-filled novel environment. We refer to this as an "unsupervised learning" experience.

All rats were handled prior to the experiment. On the day of the experiment, rats were allowed to explore the novel environment for 30 or 60 min; home cage controls were euthanized immediately after removal from their home cage. In what follows, we focus on changes in immunostaining in the hippocampus and dentate gyrus, although it was also evident that behavioral experience activated p-rpS6 in populations of neurons throughout the forebrain.

Immunostaining for $\mathrm{p}$-ser235/236 in rats that were anesthetized immediately upon removal from their home cage (Fig. 5A) 


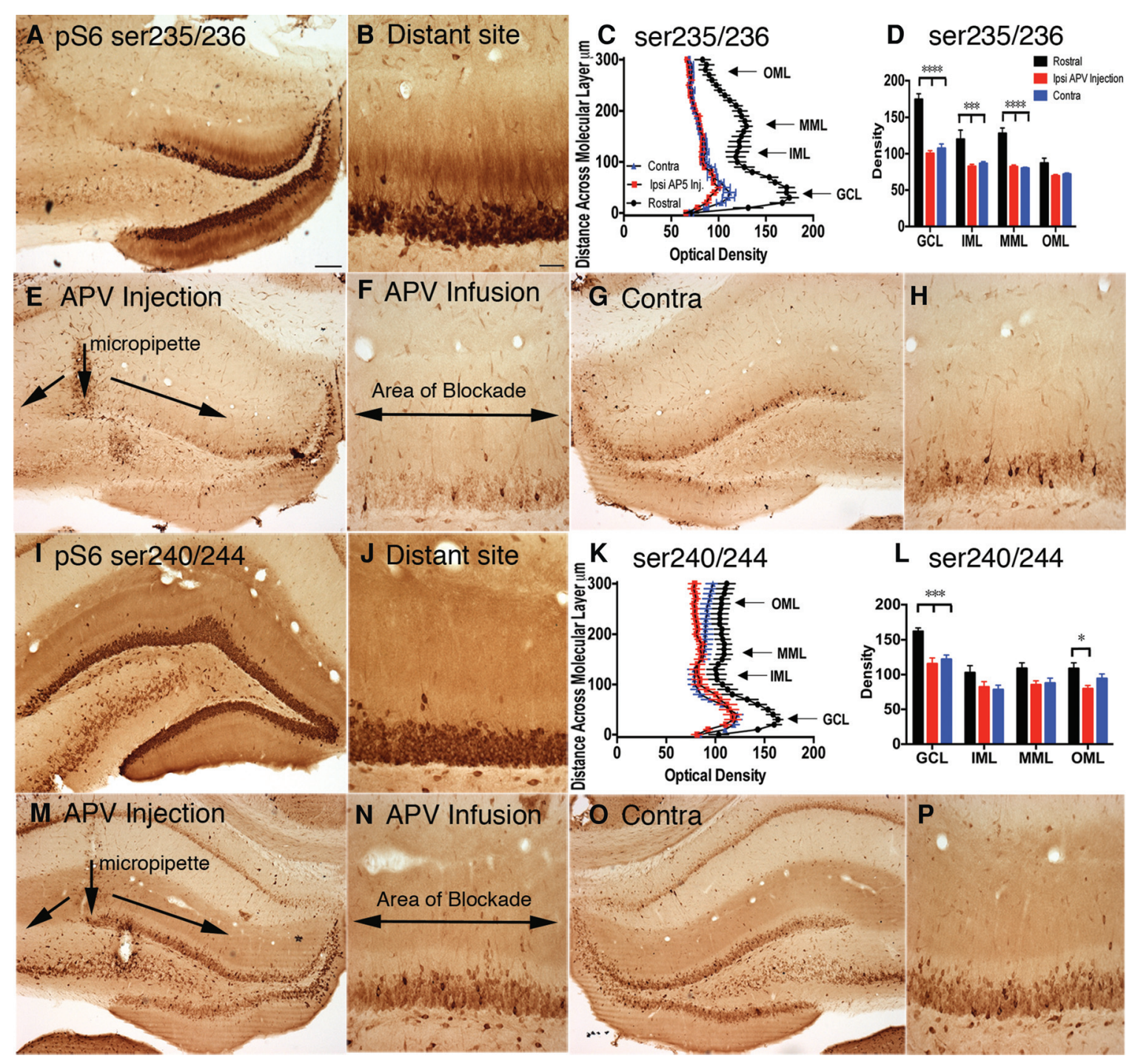

Figure 4. Phosphorylation of rpS6 is dependent on NMDA receptor activation. (A) Immunostaining of p-ser235/236 ipsilateral to stimulation in rostral section distant from the APV infusion area. (B) High-magnification image of $A$. (C) Quantification of average OD across the dorsal blade of the DG in ipsilateral section distant from the injection site (rostral), ipsilateral section within the infusion area, and contralateral section. (D) Statistical assessment at four sites along the dorsal blade of the dentate gyrus, GCL, IML, MML, OML (ser235/236, N=4), error bars represent SEM. Statistical assessment by two-way ANOVA revealed a significant interaction $\left(F_{(6,27)}=9.68, P<0.0001\right)$, a significant main effect treatment $\left(F_{(2,9)}=29.42, P=0.0001\right)$, and a significant main effect of region $\left(F_{(3,27)}=74.58, P<0.0001\right)$. Post hoc analysis with Bonferroni's correction revealed a significant difference between rostral versus injection site and contralateral $O D$ in the $G C L$, IML, and $M M L$ (two-way ANOVA, $N=4, P<0.05$ ). (E) Immunostaining of $p$-ser235/236 within the injection site in the presence of NMDAR antagonist, APV. (F) High-magnification image of $E$. (G) Immunostaining of p-ser235/236 contralateral to stimulation. (H) High-magnification image of $G$. (I) Immunostaining of p-ser240/244 ipsilateral to stimulation in section distant from the APV injection site. (J) High-magnification image of $I$. (K) Quantification of average OD across the dorsal blade of the dentate gyrus in ipsilateral section distant from the injection site (caudal), ipsilateral section within the infusion area, and contralateral section. (L) Statistical assessment at four sites along the dentate gyrus, GCL, IML, MML, OML (ser240/244, N =4), error bars represent SEM. Statistical assessment by two-way ANOVA revealed a significant interaction $\left(F_{(6,27)}=2.88, P=\right.$ $0.0267)$ a significant main effect of treatment $\left(F_{(2,9)}=6.95, P=0.0149\right)$, and a significant main effect of region $\left(F_{(3,27)}=71.19, P<0.0001\right)$. Post hoc analysis with Bonferroni's correction revealed a significant difference between rostral versus injection site and contralateral OD in the GCL and a significant difference between rostral versus injection site OD in the OML. $(M)$ Immunostaining of p-ser240/244 within the injection site in the presence of NMDAR antagonist, APV. $(N)$ High-magnification image of $M$. (O) Immunostaining of p-ser240/244 contralateral to the stimulation. $(P)$ High-magnification image of $O$. Scale bars: $A, 200 \mu \mathrm{m} ; B, 50 \mu \mathrm{m}$.

revealed scattered dentate granule cells that exhibited relatively high levels of p-rpS6 immunostaining (Fig. 5D). The labeling of a few scattered granule cells, especially in the dorsal blade of the dentate gyrus, is similar to what is seen with immunocytochemistry or in situ hybridization for IEGs under basal conditions. There were also a small number of scattered pyramidal neurons in CA1 that exhibited higher levels of immunostaining in cell bodies (Fig. 5G). Pyramidal neurons in CA3 exhibited moderate levels of immunostaining predominately in the cell bodies (Fig. 5J). It was noteworthy that overall levels of immunostaining over the neuropil layers qualitatively appeared higher than in rats that had been maintained under anesthesia for prolonged periods, consistent with the finding that synaptic activity drives p-rpS6. We did not quantify this directly, however.

Following 30 min of exploration (Fig. 5B) there were increases in the level of p-rpS6 immunostaining of neuronal cell bodies in 

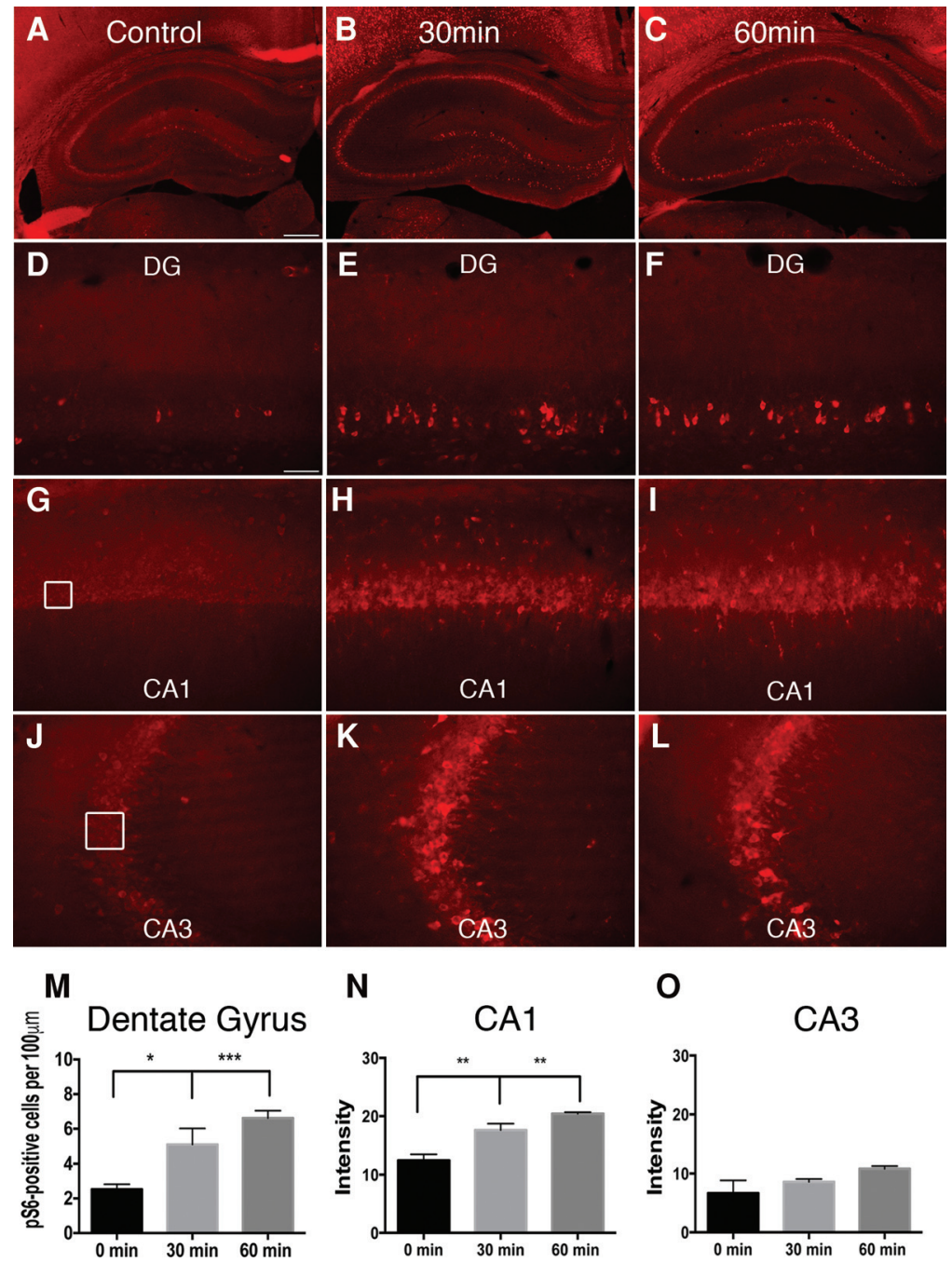

$\mathbf{N}$

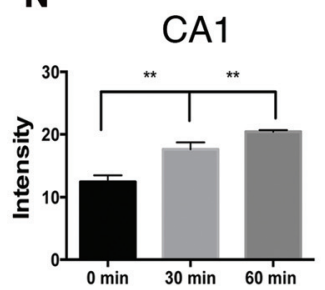

0

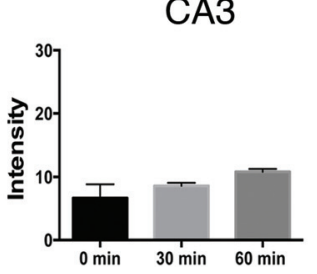

Figure 5. Exploration of a novel environment leads to increases in the number of p-ser 235 236-positive neurons. (A) Immunostaining for p-ser235/236 in the hippocampus of a cage control animal. (B) Immunostaining for p-ser235/236 in the hippocampus following $30 \mathrm{~min}$ of unsupervised learning. (C) Immunostaining of p-ser235/236 in the hippocampus following $60 \mathrm{~min}$ of unsupervised learning. (D) High-magnification image of DG in image $A$. (E) High-magnification image of DG in image $B$. $(F)$ High-magnification image of DG in image $C$. (G) High-magnification of CA1 in image $A$. (H) Highmagnification of CA1 in image $B$. (I) High-magnification of CA1 in image $C$. $(J)$ High-magnification of $C A 3$ in image $A$. (K) High-magnification of CA3 in image $B$. (L) High-magnification of CA3 in image $C$. $(M)$ Quantification of the number of p-rpS6-positive granule cells in the dorsal blade of the dentate gyrus per $100 \mu \mathrm{m}$, error bars represent SEM. Statistical assessment of the number of p-rpS6-positive cells in the granule cell layer of the DG by one-way ANOVA revealed an overall $F_{(2,15)}=11.20, P=$ 0.0011 . Post hoc analysis with Dunnett's for multiple comparisons revealed a significant difference between control animals and animals that experienced $30 \mathrm{~min}$ and $60 \mathrm{~min}$ of unsupervised learning (one-way ANOVA, $P<0.05, N=6$ ). ( $N$ ) Quantification of average OD in the pyramidal cell layer of CA1, error bars represent SEM. Statistical assessment of the average OD in the pyramidal cell layer of CA1 by one-way ANOVA revealed an overall $F_{(2,6)}=22.29, P=0.0017$. Post hoc analysis with Dunnett's for multiple comparisons revealed a significant difference between control animals and animals that experienced 30 and 60 min of unsupervised learning (one-way ANOVA, $P<0.05, N=$ 3). (O) Quantification of average OD in the pyramidal cell layer of CA3, error bars represent SEM. Statistical assessment of the average OD in the pyramidal cell layer of CA3 by one-way ANOVA revealed an overall $F_{(2,6)}=2.556, P=0.1574, N=3$. Scale bars: $A, 500 \mu \mathrm{m} ; D, 50 \mu \mathrm{m}$.

the dentate gyrus, CA1 and CA3 (Fig. 5E,H,K, respectively). The pattern of immunostaining was qualitatively similar after 60 min (Fig. 5F,I,L). Note also the large number of p-rpS6-positive neurons in the neocortex in Figure 5B and C. Notably, p-rpS6-positive cells with astrocyte morphology were also evident in the molecular layer of the dentate gyrus, stratum oriens, and stratum radiatum of CA1-CA3 following unsupervised learning (more on this below). As one measure of activation of p-rpS6, p-rpS6-positive granule cells were counted along the length of the granule cell layer of the dorsal blade of the dentate gyrus $(\sim 400 \mu \mathrm{m}$ length). The number of p-rpS6-positive granule cells was twofold higher after $30 \mathrm{~min}$ of exploration and increased further after $60 \mathrm{~min}$ (one-way ANOVA, $F_{(2,15)}=11.43$, $P=0.0010, N=6)$. Post hoc analysis using a Dunnett's multiple comparisons test revealed that differences were significant at both 30- and 60-min time points (Fig. 5M; $P<0.05$ ).

To measure the extent of p-rpS6 in the densely packed pyramidal layer of CA1 and CA3, fluorescence intensity (FI) was measured within a boxed region centered in the pyramidal cell layer (see Fig. 5G and J, respectively) and the FI was averaged along the length of the pyramidal cell layer using ImageJ software. For CA1, FI was measured in a $40 \times 40$ $\mu \mathrm{m}$ box centered along the pyramidal cell layer and statistical assessment by one-way ANOVA revealed an overall $F_{(2,6)}=22.29, P=0.0017(N=3$ rats per time point). Post hoc analysis using a Dunnett's multiple comparisons test revealed that differences were significant at both 30- and 60-min time points (Fig. 5N; $P<0.05$ ). For CA3, FI was measured in a $50 \times 50 \mu \mathrm{m}$ box centered along the pyramidal cell layer and statistical assessment by one-way ANOVA of the average IF in the pyramidal cell layer yielded an overall $F_{(2,6)}=2.556, \quad P=$ 0.1574 (Fig. 5O; $N=3$ rats per time point).

Similarly, immunostaining for p-ser240/244 in rats that were anesthetized immediately upon removal from their home cage (Fig. 6A) revealed scattered dentate granule cells that exhibited high levels of p-rpS6 immunostaining (Fig. 6D) and higher basal level immunostaining in granule cell bodies compared with p-ser235/236 (Fig. 5D). There were also a small number of scattered pyramidal neurons in CA1 that exhibited higher levels of immunostaining in cell bodies (Fig. 6G). Pyramidal neurons in CA3 exhibited high levels of immunostaining predominately in the cell bodies (Fig. 6J).

Following $30 \mathrm{~min}$ of exploration (Fig. 6B) there were increases in the level of p-rpS6 immunostaining of neuronal cell bodies in the dentate gyrus, CA1 and CA3 (Fig. 6E,H,K, respectively). The pattern of immunostaining was qualitatively similar after 60 min (Fig. 6F,I,L) with a further increase in the number of p-rpS6-positive neuronal cell bodies and increased dendritic immunostaining. p-rpS6-positive cells with astrocyte morphology were also evident in the molecular layer of the dentate gyrus, 


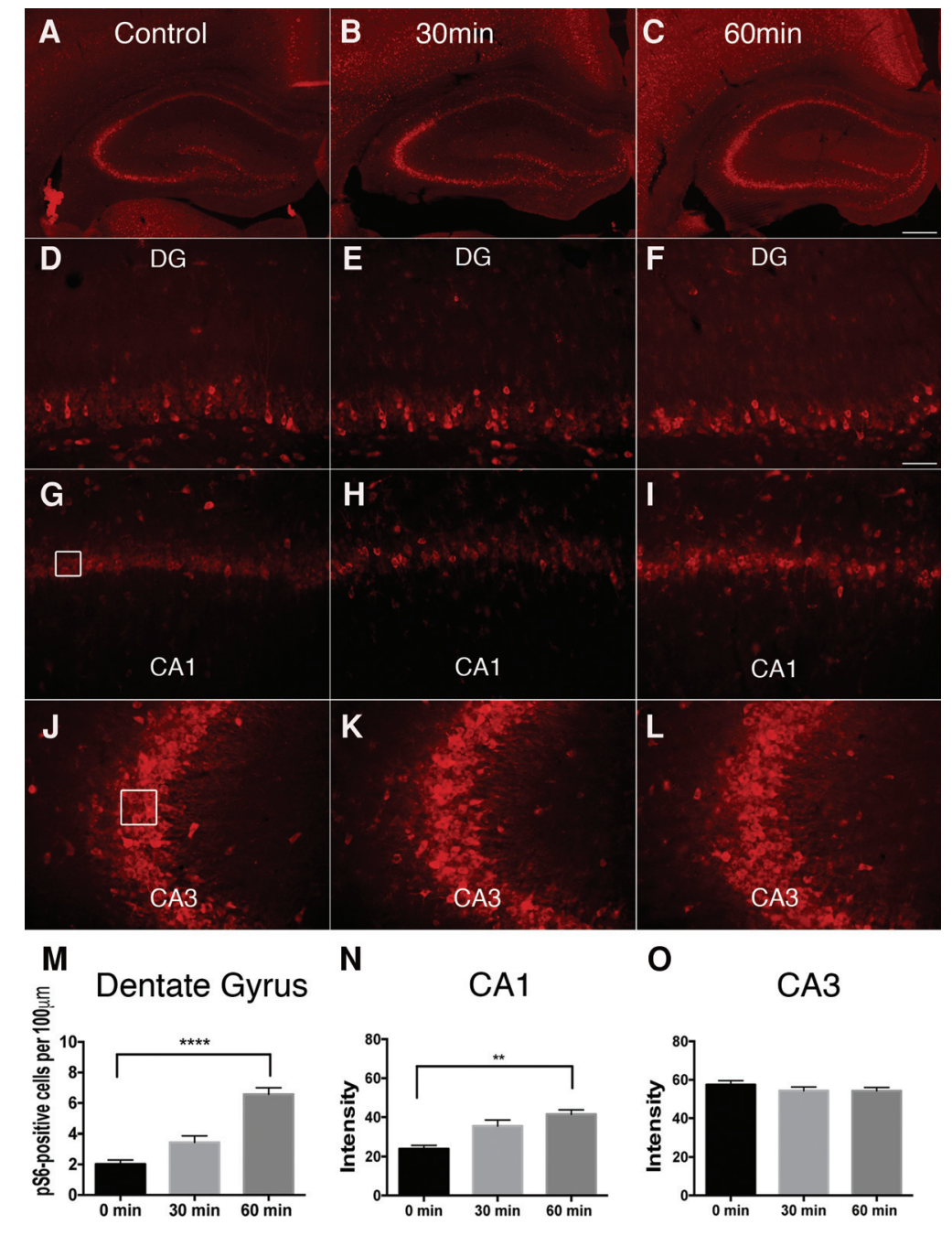

Figure 6. Exploration of a novel environment leads to increases in the number of p-ser240/ 244-positive neurons. (A) Immunostaining for p-ser240/244 in the hippocampus of a cage control animal. (B) Immunostaining for p-ser240/244 in the hippocampus following $30 \mathrm{~min}$ of unsupervised learning. (C) Immunostaining of p-ser240/244 in the hippocampus following 60 min of unsupervised learning. $(D)$ High-magnification image of DG in image $A$. $(E)$ High-magnification image of DG in image $B$. $(F)$ High-magnification image of DG in image $C$. (G) High-magnification of CA1 in image $A$. $(H)$ High-magnification of CA1 in image $B$. (I) High-magnification of CA1 in image $C$. (J) High-magnification of CA3 in image $A$. (K) High-magnification of CA3 in image $B$. (L) High-magnification of $C A 3$ in image $C .(M)$ Quantification of the number of p-rpS6-positive granule cells in the dorsal blade of the dentate gyrus per $100 \mu \mathrm{m}$, error bars represent SEM. Statistical assessment of the number of p-rpS6-positive cells in the granule cell layer of the DG by one-way ANOVA revealed an overall $F_{(2,6)}=35.52, P=0.0005$. Post hoc analysis with Dunnett's for multiple comparisons revealed a significant difference between control animals and animals that experienced $60 \mathrm{~min}$ of unsupervised learning (one-way ANOVA, $P<0.05, N=3$ ). ( $N$ ) Quantification of average OD in the pyramidal cell layer of CA1, error bars represent SEM. Statistical assessment of the average OD in the pyramidal cell layer of CA1 by one-way ANOVA revealed an overall $F_{(2,6)}=12.95$, $P=0.0067$. Post hoc analysis with Dunnett's for multiple comparisons revealed a significant difference between control animals and animals that experienced $60 \mathrm{~min}$ of unsupervised learning (one-way ANOVA, $P<0.05, N=3$ ). (O) Quantification of average OD in the pyramidal cell layer of CA3, error bars represent SEM. Statistical assessment of the average OD in the pyramidal cell layer of CA3 by one-way ANOVA revealed an overall $F_{(2,6)}=0.8796, P=0.4624, N=3$. Scale bars: $C, 500$ $\mu \mathrm{m} ; F, 50 \mu \mathrm{m}$.

stratum oriens, and stratum radiatum of CA1-CA3 following unsupervised learning. Quantification of the number of p-rpS6positive granule cells along the length of the granule cell layer of the dorsal blade of the dentate gyrus ( $\sim 400 \mu \mathrm{m}$ length) revealed a 1.6-fold increase after $30 \mathrm{~min}$ and a threefold increase after 60 min of exploration (one-way ANOVA, $F_{(2,6)}=35.52, P=0.0005$,
$N=3$ ). Post hoc analysis using a Dunnett's multiple comparisons test revealed a significant difference at the 60 -min time point (Fig. 6M; $P<0.05$ ).

Quantification of FI in CA1 and statistical assessment by one-way ANOVA revealed an overall $F_{(2,6)}=12.95, \quad P=$ 0.0067 ( $N=3$ rats per time point). Post hoc analysis using a Dunnett's multiple comparisons test revealed that differences were significant at the 60-min time point (Fig. $6 \mathrm{~N} ; P<0.05$ ). For CA3, quantification of FI and statistical assessment by one-way ANOVA of the average IF in the pyramidal cell layer yielded an overall $F_{(2,6)}=0.8796, P=0.4624$ (Fig. 6O; $N=3$ rats per time point). It is important to note that AF564 was used as a secondary for p-ser235/236 while AF 546 was used as a secondary on p-ser240/244 immunostaining. As a result, intensity values are higher for p-ser240/244 on CA1 and CA3 graphs.

\section{Coactivation of rpS6 phosphorylation and IEG transcription in individual neurons}

The activation of p-rpS6 in individual neurons as a result of experience is reminiscent of what is seen with IEG transcription, including Arc. To assess whether a learning experience triggers p-rpS6 in the same neurons in which Arc is induced, brains were coimmunostained for Arc protein and the p-ser235/ 236 antibody (Fig. 7). We focused on the dentate granule cells because experience-dependent increases in the number of Arc positive neurons have been well characterized (Guzowski et al. 1999; Ramirez-Amaya et al. 2005; Vazdarjanova et al. 2006). In home cage controls, there were only a few p-rpS6positive or Arc protein-positive granule cells (Fig. 7A,B, respectively). Many neurons were positive for both p-rpS6 and Arc protein (Fig. 7C). Following unsupervised learning, there was a striking increase in the number of p-rpS6-positive and Arc protein-positive granule cells, and again, many individual neurons but not all were positive for both p-rpS6 and Arc protein (Fig. 7D-I).

Consistent with previous findings on Arc, we noted that the increase in the number of Arc protein-positive and p-rpS6-positive granule cells appeared more pronounced in the septal pole of the hippocampus than in the temporal pole. This, however, was not analyzed in detail.

To quantify the extent of colabeling, the number of p-rpS6 and Arc protein-positive cells were counted within a boxed region $(120 \times 200 \mu \mathrm{m})$ centered in the dentate gyrus cell body 


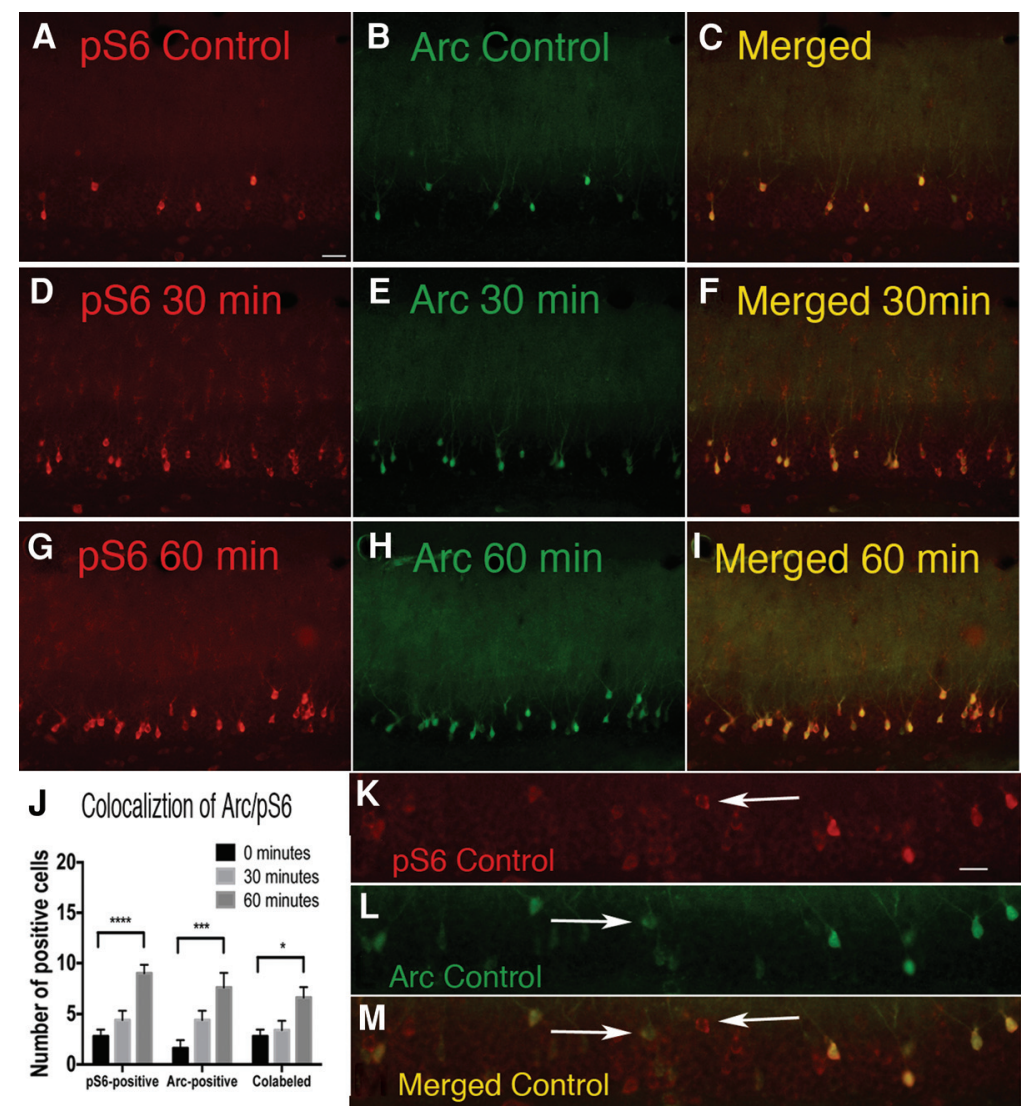

Figure 7. Exploration of a novel environment leads to increases in the number of coactivated p-rpS6-positive and Arc protein-positive neurons in the granule cell layer of the dentate gyrus. $(A)$ Pattern of immunostaining for $\mathrm{p}$-ser235/236 in cage control animal as revealed by immunofluorescence. $(B)$ Pattern of immunostaining for Arc protein in cage control animal as revealed by immunofluorescence. (C) Merged image of $A$ and $B$. (D) Pattern of immunostaining for p-ser235/236 following 30 min of unsupervised learning as revealed by immunofluorescence. $(E)$ Pattern of immunostaining for Arc protein following $30 \mathrm{~min}$ of unsupervised learning as revealed by immunofluorescence. $(F)$ Merged image of $D$ and $E$. (G) Pattern of immunostaining for $p$-ser235/236 following 60 min of unsupervised learning as revealed by immunofluorescence. $(H)$ Pattern of immunostaining for Arc protein following $60 \mathrm{~min}$ of unsupervised learning as revealed by immunofluorescence. (I) Merged image of $G$ and $H .(J)$ Quantification of the number of p-rpS6-positive, Arc protein-positive and colabeled cells following an unsupervised learning experience, error bars represent SEM. Statistical assessment of the number of p-rpS6, Arc protein-positive cells and colabeled cells by two-way ANOVA yielded an overall $F_{(4,24)}=4.04, P=0.0120$. Post hoc analysis with Dunnett's for multiple comparisons revealed a significant difference in the number of activated neurons between control animals and animals that experienced $60 \mathrm{~min}$ of unsupervised learning for p-rpS6-positive, Arc protein-positive and colabeled conditions. (K) Pattern of immunostaining for p-ser235/236 in a cage control animal. Arrow shows a p-rpS6 positive cell that is not Arc protein-positive. ( $L$ ) Pattern of immunostaining for Arc protein in cage control animal. Arrow shows Arc protein-positive cell that is not p-rpS6-positive. $(M)$ Merged image of $K$ and $L$. Arrows show single p-rpS6-positive and Arc protein-positive cells. Scale bars: $A$, $50 \mu \mathrm{m} ; K, 20 \mu \mathrm{m}$.

layer (Fig. 7J). Statistical analysis of the number of p-rpS6, Arc protein-positive cells and colabeled cells in each group by twoway ANOVA yielded an overall $F_{(4,24)}=3.06, P=0.0361, N=5$. Post hoc analysis using a Dunnett's multiple comparisons test revealed a significant difference between control animals and animals that experienced $60 \mathrm{~min}$ of unsupervised learning for p-rpS6-positive, Arc protein-positive and colabeled neurons. Overall, in cage controls, $60 \%$ of Arc protein positive cells were colabeled with p-rpS6 and 56\% of p-rpS6-positive cells were colabeled with Arc protein. In animals that explored the novel environment, $90 \%$ of Arc protein-positive cells were colabeled with p-rpS6 and 73\% of the p-rpS6-positive cells were colabeled with Arc protein (Table 1).

\section{Learning induced phosphorylation of rpS6 in astrocytes and interneurons}

As noted above, there were numerous p-rpS6-positive cells with astrocyte morphology in the dendritic layers of the DG, CA1-CA3 regions following unsupervised learning (Fig. 5E,F,H,I,K,L), which were not evident in home cage controls (Fig. 5D,G,J). Coimmunostaining for p-ser235/236 (Fig. 8A) and glial fibrillary acidic protein (GFAP) (Fig. 8B) revealed that p-rpS6-positive cells with astrocyte morphology were GFAP-positive (Fig. 8C).

The presence of p-rpS6-positive cells with neuronal morphology in the dendritic laminae of the DG, CA1, and CA3 raised the question of whether these might be inhibitory interneurons. Coimmunostaining for parvalbumin (PV), p-rpS6, and Arc protein revealed that some p-rpS6-positive cells in the molecular layer of the dentate gyrus, and stratum oriens and stratum radiatum of CA1-CA3 were also positive for PV (Fig. $8 \mathrm{~F}, \mathrm{I})$. In some cases, immunostaining for p-rpS6 was primarily in the cell body whereas immunostaining for PV extended into dendrites (Fig. 8D-F). Some PV-positive cells also immunostained for Arc protein. Figure 8G-I illustrate two Arc protein-positive cells one of which is also PV-positive. Taken together these results indicate that learning induced p-rpS6 is found in a variety of cell types from principal cells to interneurons to astrocytes.

\section{Robust increases in rpS6 phosphorylation are not accompanied by increases in protein synthesis}

Increases in p-rpS6 could indicate an increase in overall levels of protein synthesis or a shift in translation from one population of mRNAs to another without altering overall levels of translation. To test the hypothesis that induction of rpS6 phosphorylation leads to an overall increase in protein synthesis, HFS was unilaterally delivered for 30 or 90 min to the perforant path to generate maximal p-rpS6, C14-leucine $(50-70 \mu \mathrm{Ci}$ per $250 \mathrm{~g}$ of body weight) was administered via tail vein injection at the start of 30-min HFS or $30 \mathrm{~min}$ prior to the end of stimulation for 90-min HFS. Rats were then perfused and prepared for autoradiographic assessment. Surprisingly, there were no differences in labeling on the stimulated side compared with nonstimulated side (Fig. 9). To quantify labeling, images of the dentate gyrus were used to measure the average OD over the GCL and dendritic laminae as illustrated in Figure 9C and D. OD values were then calculated as an I/C ratio (Fig. 9E) and expressed as a percent change (Fig. 9F). As illustrated in the bar graphs, average I/C ratios were near 1.0 (Fig. 9E and F; two-way ANOVA, $F_{(3,15)}=0.96, P=0.4358, N=3$ for 30 
Table 1. Percent of colabeled p-rpS6-positive and Arc protein-positive granule cells

\begin{tabular}{lcc}
\hline $\begin{array}{l}\text { Unsupervised } \\
\text { learning }\end{array}$ & $\begin{array}{c}\text { \% p-rpS6-positive } \\
\text { granule cells colabeled }\end{array}$ & $\begin{array}{c}\text { \% Arc-positive } \\
\text { granule cells } \\
\text { colabeled }\end{array}$ \\
\hline Cage control & 56 & 60 \\
$30 \mathrm{~min}$ & 64 & 72 \\
$60 \mathrm{~min}$ & 73 & 90 \\
\hline
\end{tabular}

Percent of colabeled p-rps6-positive cells were calculated by dividing the number of colabeled cells over the total p-rpS6-positive cells. Percent of colabeled Arc protein-positive cells were calculated by dividing the number of colabeled cells over the total Arc protein-positive cells.

min and $N=4$ for 90 min), indicating no change in protein synthesis despite the dramatic increases in p-rpS6.

\section{Discussion}

Our results confirm previous findings that patterns of synaptic activity that induce LTP induce phosphorylation of rpS6 (p-rpS6) in postsynaptic neurons (Panja et al. 2009) and reveal several novel findings including: (1) Activation of p-ser235/236 occurs locally and is especially robust in the region of the activated synapses, whereas this localized activation is less prominent with p-ser240/ 244; (2) Induction of phosphorylation depends on NMDA receptor activation; (3) Following LTP induction, p-rpS6 peaks 30 min post-stimulation, a time at which IEG transcripts are available in quantity for translation; (4) Experience activates p-rpS6 in many of the same neurons in which IEG expression is induced; (5) robust p-rpS6 is not associated with global increases in protein synthesis.

\section{Selective activation of rpS6 phosphorylation near active synapses}

Strong synaptic activation triggers selective induction of phosphorylation of ser235/236 in activated dendritic domains; this was less evident with p-ser240/244. This differential pattern of activation could reflect differences in the signaling pathways through which phosphorylation is induced. Phosphorylation of rpS6 occurs at five serine residues (Krieg et al. 1988) in sequence starting with ser236, ser235, ser240, ser244, then ser247 (Flotow and Thomas 1992; Wettenhall et al. 1992). It has been reported that ser240/244 is predominately mTOR-dependent being phosphorylated by S6K1 and S6K2 (Pende et al. 2004). In contrast, ser235/236 has been implicated as a target for multiple signaling pathways including MAPK/ERK via RSK (Roux et al. 2007) and PKA (Gobert et al. 2008; Moore et al. 2009; Biever et al. 2015a). Thus, the relatively higher activation in the region of active synapses for p-ser235/236 could be because it integrates signals from multiple pathways.

The more robust increase in immunostaining in the region of active synapses for p-ser235/236 invites the speculation that induction of p-ser235/236 is especially important for regulating local translation of mRNAs at synapses. In this regard, a recent study has reported transient translocation of rpS6 into spines of dentate granule cells following induction of perforant path LTP (Nihonmatsu et al. 2015), which were seen at 15 min but not 35 min after LTP induction.

\section{Phosphorylation of rpS6 is driven by NMDA receptor activation}

Synaptically driven phosphorylation of rpS6 was completely blocked by local infusion of the NMDA receptor antagonist,
APV, which is noteworthy because NMDA receptor activation is required for LTP induction (Harris et al. 1984; Wigström and Gustafsson 1986). This finding links activation of p-rpS6 with other events that occur during LTP induction including activation of intracellular signaling pathways (for review, see Bliss and Collingridge 1993; Cortes-Mendoza et al. 2013) that involve $\mathrm{Ca}^{2+} / \mathrm{CaM}$-dependent protein kinase (Lynch and Baudry 1984; Malenka et al. 1989; Bading et al. 1993), PI3K and S6-kinase (Cammalleri et al. 2003; Lenz and Avruch 2005), and MAPK (Impey et al. 1998; Kelleher et al. 2004b). The fact that LTP-inducing stimuli induces p-rpS6 in an NMDA receptordependent fashion documents a molecular correlate of synaptic plasticity, but it remains to be determined whether there is a mechanistic link.

\section{Phosphorylation of rpS6 is activated by behavioral experience}

A learning experience (exploration of a novel environment) induced p-rpS6 in individual neurons scattered throughout the forebrain in a pattern that is similar to what is seen with IEG induction. Moreover, coimmunostaining revealed experiencedependent activation of p-rpS6 in many of the same individual neurons in which IEGs are activated. Previous studies have shown that exploration of a novel environment strongly induces Arc expression in neurons in CA1 and CA3 from 30 min up to $2 \mathrm{~h}$ postexploration (Ramirez-Amaya et al. 2005). In the dentate gyrus, Arc is induced in scattered granule cells especially in the dorsal blade of the dorsal hippocampus from 30 min up to $8 \mathrm{~h}$ post-exploration (Ramirez-Amaya et al. 2005). Additional studies also document changes in expression of IEGs following natural synaptic activity
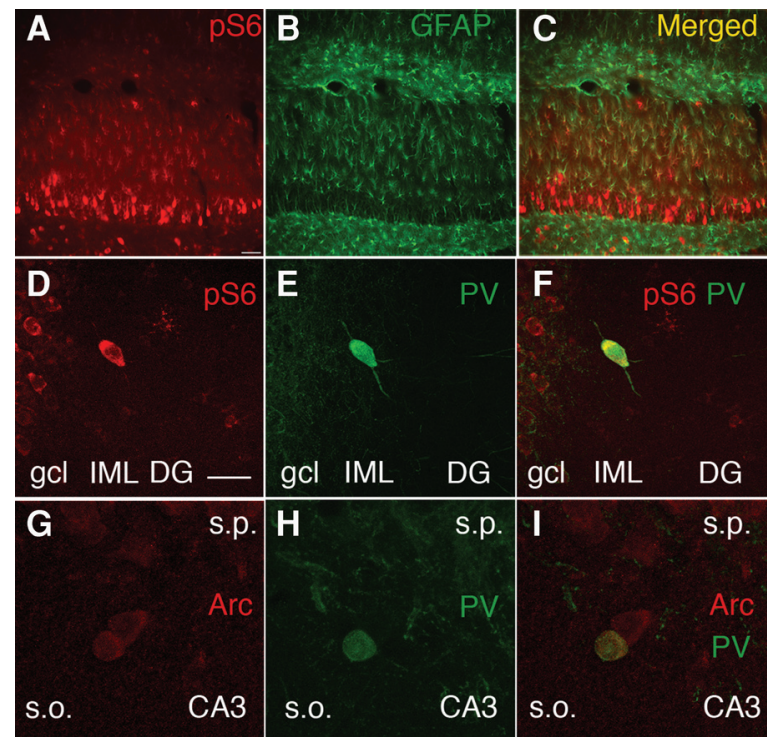

Figure 8. Learning induced phosphorylation of rpS6 in astrocytes and interneurons. (A) Pattern of immunostaining of p-ser235/236 following $60 \mathrm{~min}$ of unsupervised learning. (B) Pattern of immunostaining of GFAP following $60 \mathrm{~min}$ of unsupervised learning. (C) Merged image of image $A$ and $B$. (D) Immunostaining of p-ser235/236 in the IML of the DG. $(E)$ Immunostaining of PV-positive cell in the IML of the DG. $(F)$ Merged image of $D$ and $E$. Image shows colabeled interneuron in the IML of the DG in a cage control. $(G)$ Immunostaining of Arc protein in stratum oriens of CA3. $(H)$ Immunostaining of PV-positive cell in s.o. of CA3. (I) Merged image of image $G$ and $H$. Image shows two Arc-positive cells in s.o. of CA3, one of which colocalizes with a PV-positive cell. Scale bars: $A, 50 \mu \mathrm{m} ; \mathrm{I}, 30 \mu \mathrm{m}$. IML, inner molecular layer; DG, dentate gyrus; s.o., stratum oriens; s.p., stratum pyramidale. 

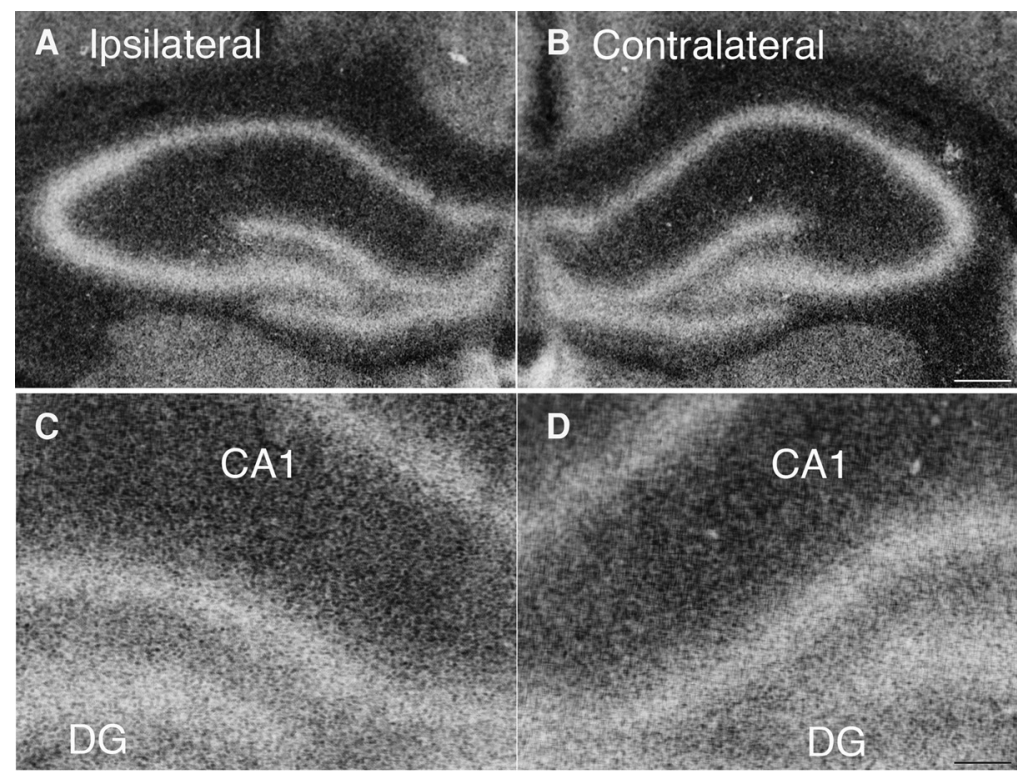

E

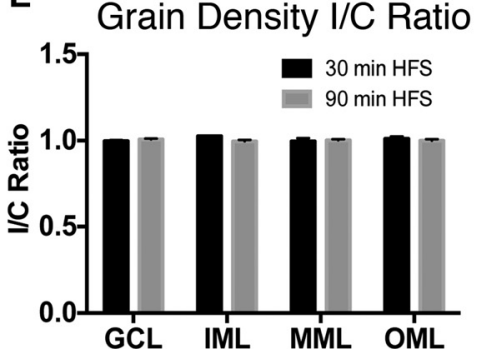

\section{$\mathbf{F}$}

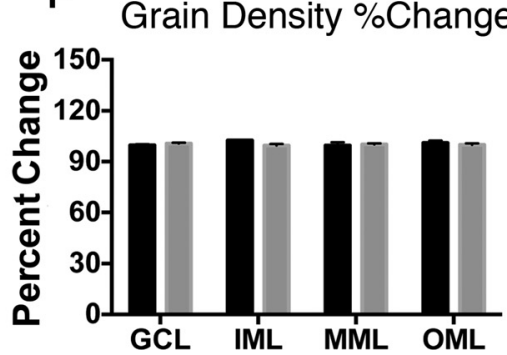

Figure 9. Robust increases in $\$ 6$ phosphorylation does not result in increases in global protein synthesis. (A) $4 \times$ magnification image of autoradiograph film ipsilateral to stimulation following 90 min of HFS. (B) $4 \times$ magnification image of autoradiograph film contralateral to stimulation (nonstimulated) following 90 min of HFS. (C) High-magnification image of $A$. (D) High-magnification image of $B$. (E) Quantification of ipsilateral/contralateral ratio following 30 or 90 min of HFS, error bars represent SEM. (F) Quantification of percent change from contralateral following 30 or 90 min of HFS, error bars represent SEM. Statistical assessment of average grain density were then calculated as an I/C ratio and expressed as a percent change. Statistical analysis of the percent change in average grain density by two-way ANOVA yielded an overall $F_{(3,20)}=1.01, P=0.4104(N=3$, for 30 min and $N=$ 4 for 90 min; two-way ANOVA, $P<0.05)$. Scale bars: $B, 200 \mu \mathrm{m} ; D, 100 \mu \mathrm{m}$.

(Worley et al. 1991) and increased expression in CA1 and CA3 subfields following spatial memory tasks (Vazdarjanova et al. 2006) with a dominance in CA1 (Hess et al. 1995; Guzowski et al. 1999; Vann et al. 2000). Given the evidence that Arc induction is critical for both LTP and long-term memory (Guzowski et al. 2000; Bramham et al. 2008), the high degree of coactivation suggests that both may play a role in activity-dependent synaptic plasticity.

Our findings that a learning experience induces both p-rpS6 and IEG transcription in individual neurons adds to previous findings implicating mTOR activation and its downstream substrates in learning and memory (Jacinto and Hall 2003; Dash et al. 2006; Antion et al. 2008b; Hoeffer and Klann 2010). For example, radial arm maze training triggers mTOR activation and phosphorylation of its downstream substrates, 4EBP1 and p70S6K, and infusion of rapamycin inhibited mTOR activation and retarded acquisition (Qi et al. 2010). Indeed, S6K is induced in several brain regions following other types of training (Belelovsky et al. 2005; Dash et al. 2006; Parsons et al. 2006; Bekinschtein et al. 2007).

Surprisingly, experience also induced p-rpS6 in astrocytes in the hippocampus, which was not seen following HFS. This activa- tion of p-rpS6 in astrocytes may indicate events in astrocytes that are activated uniquely under conditions of behavioral learning but not HFS. Alternatively, activation of p-rpS6 in astrocytes may be uniquely sensitive to urethane anesthesia. In either case, the fact behavioral experience strongly regulates p-rpS6 in astrocytes raises the provocative idea of behavioral regulation of mRNA translation in astrocytes.

\section{Robust phosphorylation of rpS6 is not accompanied by increases in global protein synthesis}

Induction of p-rpS6 occurs under conditions that lead to increases in protein synthesis (Duncan and McConkey 1982; Thomas et al. 1982; Jefferies and Thomas 1996) including mitogenic stimulation (Gressner and Wool 1974), or treatment with hormones (Smith et al. 1979), growth factors (Thomas et al. 1982), and nutrients (Proud 2002). Nevertheless, our results document that there are no detectable increases in global protein synthesis when rpS6 phosphorylation is strongly activated by synaptic stimulation. If p-rpS6 is regulating translation following induction of perforant path LTP, it is not reflected in overall levels of incorporation of amino acid precursors in dentate granule cells.

The absence of any increase in protein synthesis with perforant path LTP is surprising because of previous studies of LTP in hippocampal slices in vitro. Previous studies have reported increases in 35S-methionine incorporation (Kelleher et al. 2004b), induced expression of 5TOP mRNAs (Tsokas 2005; Tsokas et al. 2007; Gobert et al. 2008), and increases in protein synthesis (Kelleher et al. 2004b; Klann and Dever 2004; Antion et al. 2008a) after LTP induction. One possible explanation is that mechanisms of perforant path LTP are different than forms of LTP studies in hippocampal slices in vitro. Differences may also be due to technical variables. For example, in the study of Kelleher et al, the slice medium was artificial cerebral spinal fluid, and it is not reported whether it was supplemented with amino acids. It is possible that their results depended on the fact that the pulselabeling was under conditions of short-term amino acid starvation. Under these conditions, proteins critical for structural remodeling and consolidation may be depleted (Lynch et al. 2014). In this regard, it is noteworthy that the consequences of protein synthesis inhibitors also depend on the time of application (Kelleher et al. 2004a).

Our finding of no detectable difference in global protein synthesis in the dentate gyrus despite robust induction of p-rpS6 is in line with other reports (Biever et al. 2015a). However, the lack of increase in global protein synthesis does not rule out the possibility that p-rpS6 may be involved in the preferential translation of specific mRNAs (Jefferies 1997). It may be that the population of mRNAs whose translation is regulated by p-rpS6 is so small in number that changes in their translation rate would not be 
reflected in overall protein synthesis levels. Alternatively, p-rpS6 may initiate translation of a subset of mRNAs at the same time that translation of other mRNAs is decreased, resulting in no overall change. Finally, it is also possible that p-rpS6 may be involved in other roles besides translation (Biever et al. 2015b; Meyuhas 2015). Further studies will be required to assess these possibilities.

\section{Materials and Methods}

\section{Animals}

Experimental animals were adult female (150-300 g) SpragueDawley rats from Harlan laboratories (Hsd). Rats were anesthetized with $20 \%$ urethane and positioned in a stereotaxic apparatus as described previously (Steward et al. 1998). All experimental procedures were approved by the Institutional Animal Care and Use Committee (IACUC) of the University of California, Irvine.

\section{Acute neurophysiology preparation}

Acute neurophysiological techniques were used to unilaterally stimulate the medial perforant path projections to the dentate gyrus. Projections from the entorhinal cortex to the dentate gyrus are predominately unilateral so the contralateral side serves as an intra-animal control. A stimulating electrode, an insulated tungsten microelectrode, was stereotaxically positioned in the medial entorhinal cortex $(4.0 \mathrm{~mm}$ lateral, $1.0 \mathrm{~mm}$ anterior to $\lambda$ within a 3.0-4.0 $\mathrm{mm}$ range below the cortical surface). Electrode depth was adjusted to obtain a maximal evoked response in the dentate gyrus with minimal stimulus intensity. Stimulus intensity was set to evoke $\sim 1.5 \mathrm{mV}$ population spike. The recording electrode, a glass micropipette filled with $0.9 \%$ saline, was positioned in the cell body layer of the dentate gyrus ( $3.5 \mathrm{~mm}$ posterior, $1.7 \mathrm{~mm}$ lateral to bregma, and $\sim 3.0 \mathrm{~mm}$ below the cortical surface). The depth of the recording electrode was adjusted to record the positive-going field potential generated by perforant path stimulation.

\section{Experimental procedure}

After positioning electrodes, test stimulation was delivered at a rate of $1 / 10 \mathrm{sec}$ to determine baseline response amplitude. Then high frequency stimulation was initiated as described below.

\section{High frequency stimulation (HFS)}

Two HFS paradigms were used. One was our standard paradigm to induce perforant path LTP; the other involved longer periods of continuous HFS (5 min to $2 \mathrm{~h}$ ), which is our standard paradigm to cause Arc mRNA to localize selectively in activated dendritic domains (Steward et al. 1998).

To induce LTP, three bouts of $10,400 \mathrm{~Hz}$ trains $(20 \mathrm{msec}$ in duration for a total of eight pulses per train) were delivered at a rate of $1 / 10 \mathrm{sec}$. Ten test responses were collected between each bout. Animals were euthanized at different times post-LTP induction $(5,15,30,60,120,240$, and $360 \mathrm{~min}, N=5$ per time point). Times are from the delivery of the first train of HFS. For the 5-min time point, only 10 trains were delivered and the rats were perfused 5 min after the first train. For the 4 and $6 \mathrm{~h}$ cases, the first 60 test responses were taken at a rate of $1 / 10 \mathrm{sec}$ and then test responses were taken at $1 / 30 \mathrm{sec}$ for the remaining time.

Longer periods of HFS involved delivery of three bouts of $10,400 \mathrm{~Hz}$ trains followed by test stimulation to determine extent of LTP, then continuing HFS at a rate of $1 / 10$ sec for periods ranging up to $2 \mathrm{~h}$. For the 5-min time point, $30,400 \mathrm{~Hz}$ trains were delivered at $1 / 10 \mathrm{sec}$. At the designated survival interval, rats received a lethal dose of Euthasol $(0.5 \mathrm{~mL})$ or Fatal plus $(1.0 \mathrm{~mL})$ and were perfused with $4 \%$ paraformaldehyde.

\section{Local drug infusions}

Stimulating and recording electrodes were positioned as described above, and baseline response amplitude was assessed using a saline-filled recording electrode. The saline filled microelectrode was then replaced with a microelectrode filled with the NMDAR antagonist, APV, $(51 \mathrm{mM}(10 \mathrm{mg} / \mathrm{mL})$ in saline; Tocris, Cat. 0106) and response amplitude was again monitored for a minimum of $10 \mathrm{~min}$. After assessing response amplitude post-drug delivery, HFS was delivered as described above.

\section{Unsupervised learning}

Adult female rats $(N=18)$ were handled for 10 min 2 times a day for $3 \mathrm{~d}$. On the day of the experiment, rats were habituated to the room for $15 \mathrm{~min}$ in their home cage. For the unsupervised learning paradigm, rats were placed in a large tank filled with numerous toys scattered inside and were allowed to explore the novel environment for 30 or $60 \mathrm{~min}$. At the end of the exploration period, rats immediately received $0.5 \mathrm{~mL}$ Euthasol and were perfused with $4 \%$ paraformaldehyde.

\section{Immunohistochemistry}

Brains were sectioned in the coronal plane on a Vibratome at 40 $\mu \mathrm{m}$ and sections were stored in phosphate buffer ( $\mathrm{pH}$ 7.4). Prior to immunostaining, free-floating sections were placed in microfuge tubes with nano pure water and then the microfuge tubes were placed in boiling water for $3 \mathrm{~min}$ for antigen retrieval. Sections were then treated with $\mathrm{H}_{2} \mathrm{O}_{2}$ for 15 min to block endogenous peroxidase activity, transferred to $0.01 \%$ Tween in PBS for $15 \mathrm{~min}$, blocked for $1-2 \mathrm{~h}$ at room temperature in tyramide signal amplification blocking buffer and then incubated for $18-20 \mathrm{~h}$ in a 1:100 dilution of rpS6 phospho-specific antibodies that recognize phosphorylated ser235/236 (Cell Signaling, \#4858) or ser240/244 (Cell Signaling, \#2215) or in a 1:100 dilution of total rpS6 (Cell Signaling, \#2217). Sections were then incubated in a 1:250 dilution of biotinylated donkey anti-rabbit IgG for $2 \mathrm{~h}$ (Jackson Laboratories, 711-065-152), treated with $\mathrm{ABC}$ for $2 \mathrm{~h}$ (Vector, PK-6100), stained for 5 min in DAB (Vector, SK-4100) and mounted on $0.5 \%$ gelatin subbed slides. Slides were dehydrated through washes of graded ethanol, cleared in three changes of xylene and cover slipped with DPX mountant for histology.

For immunofluorescence, free-floating sections underwent the same antigen retrieval and blocking of peroxidase activity but were then blocked for $1 \mathrm{~h}$ in $0.1 \%$ Triton-X 100 and $10 \%$ natural goat serum in PBS and then incubated for $18-20 \mathrm{~h}$ in a 1:100 dilution of p-ser235/236, 1:100 dilution of Arc antibody (SCB, sc17839), 1:300 dilution of GFAP antibody (Cell Signaling, \#3670) or 1:3000 dilution of anti-parvalbumin antibody (Sigma, P3088). Sections were then incubated for $2 \mathrm{~h}$ in appropriate secondary antibody (Thermo Fisher, 1:250), mounted on $0.5 \%$ gelatin subbed slides and cover slipped with Vectashield.

\section{Image quantification}

Optical density (OD) across the granule cell layer and molecular layers of the dentate gyrus was quantified using NIH ImageJ as described in detail previously (Farris et al. 2014). Images were taken at $20 \times$ using the same acquisition parameters. A line region of interest (ROI) was aligned perpendicular to the cell body layer extending through the dendritic laminae and OD was measured at every $20 \mu \mathrm{m}$. The OD at each level was averaged across the total number of line measurements per image to obtain an average value along the line ROI for each section. Figure 1 represents quantification of a single animal with $\sim 19$ line measurements averaged. For all other quantifications, the average line ROI values were then averaged across rats to generate an "average optical density versus distance" graph where $N=$ number of rats. Values are presented as mean \pm SEM.

For the assessment of changes in immunostaining after HFS across time points, values were obtained as described above except that only OD measures from two sites, the cell body layer and middle molecular layer, for both ipsilateral and contralateral sides to the stimulation are shown. The average values were plotted to represent each time point. For quantification following APV infusion, OD was measured at four sites, the cell body later, 
inner molecular layer, middle molecular layer, and outer molecular layer.

For quantification of p-rpS6 immunofluorescence following experience, images were collected at $20 \times$ magnification. P-rpS6 positive granule cells were counted along the length of the granule cell layer of the dorsal blade of the dentate gyrus $(\sim 400 \mu \mathrm{m}$ length). Levels of immunofluorescence for p-rpS6 in the pyramidal cell layers of CA1 and CA3 were assessed by centering a measuring frame $(40 \times 40 \mu \mathrm{m}, \mathrm{CA} 1 ; 50 \times 50 \mu \mathrm{m}, \mathrm{CA} 3)$ over the pyramidal cell layer (see Fig. 5G,J, respectively); fluorescence intensity was averaged along the length of the pyramidal cell layer using ImageJ software.

\section{Film autoradiography to assess protein synthesis}

To assess levels of protein precursor incorporation, rats received 30 or 90 min of continuous HFS to induce rpS6 phosphorylation and then received injections of C14-leucine $(50-70 \mu \mathrm{Ci}$ per $250 \mathrm{~g}$ of body weight) via tail vein injection immediately before HFS for the 30-min time point or $\sim 30 \mathrm{~min}$ before the end of the stimulation for the 90 -min time point. Rats were perfused with $4 \%$ paraformaldehyde immediately post-stimulation and $20-\mu \mathrm{m}$ coronal brain sections were cut on a cryostat and mounted on glass coverslips. The glass coverslips were affixed to a cardboard sheet with rubber cement. The sheet was placed in a cassette with C14-sensitive film. Exposure times ranged from 8-12 wk.

\section{Quantification of film autoradiographs}

Images of the dentate gyrus on the autoradiographic films were acquired at $10 \times$ on an upright microscope keeping exposure constant. OD was measured across the granule cell layer and molecular layers of the dentate gyrus using NIH ImageJ software. Images were converted to 8-bit grayscale and inverted so that higher density equated to a greater intensity value. Since stimulation is unilateral, comparisons were done between the stimulated versus the contralateral (control) side of the brain. A ROI was measured to be the length of the cell body layer and the dendritic laminae, aligned perpendicular to the cell body layer and line intensities were measured every $100 \mu \mathrm{m}$ along the length of the $10 \times$ image (approximately eight line measurements per image). The intensity value for each point in the line ROI was averaged across the total number of line measurements per image to obtain an average value along the line ROI for each section. Measures from four sections per animal were averaged. Intensity values for granule cell layer and molecular layers were averaged across rats then calculated as an ipsilateral/contralateral (I/C) ratio and then the values were expressed as a percent change to generate an "average grain density (\% of contralateral) versus region" graph where $N=$ number of rats. Values are presented as mean \pm SEM.

\section{Image adjustments}

The only adjustments of images were for brightness and contrast. Images of light micrographs were adjusted only to make the images appear as they do in the microscope. Paired images taken at different parts of the same section (i.e., ipsi- and contralateral to the stimulation) are shown with identical adjustments. Images of fluorescence were adjusted for the figures so that background fluorescence is comparable; images used for quantitative analysis were not adjusted.

\section{Statistical analysis}

Statistical analyses were done using Prism (GraphPad Software, San Diego, USA). For all analyses, " $N$ " = number of animals.

\section{Competing interest statement}

O.S. is a cofounder of the company called "Axonis." P.S.P. declares no competing financial interests.

\section{Acknowledgments}

Supported by National Institutes of Health (NIH) grant NS12333 (O.S.); P.S.P. was the recipient of fellowship support from NIH MBRS-IMSD GM055246, 5T32 NS045540, F31 NS083349.

\section{References}

Abraham WC, Williams JM. 2003. Properties and mechanisms of LTP maintenance. Neuroscientist 9: 463-474.

Antion MD, Hou L, Wong H, Hoeffer CA, Klann E. 2008a. mGluR-dependent long-term depression is associated with increased phosphorylation of S6 and synthesis of elongation factor 1A but remains expressed in S6K-deficient mice. Mol Cell Biol 28: 2996-3007.

Antion MD, Merhav M, Hoeffer CA, Reis G, Kozma SC, Thomas G, Schuman EM, Rosenblum K, Klann E. 2008b. Removal of S6K1 and S6K2 leads to divergent alterations in learning, memory, and synaptic plasticity. Learn Mem 15: 29-38.

Bading H, Ginty DD, Greenberg ME. 1993. Regulation of gene expression in hippocampal neurons by distinct calcium signaling pathways. Science 260: $181-186$

Barth-Baus D, Stratton CA, Parrott L, Myerson H, Meyuhas O, Templeton DJ, Landreth GE, Hensold JO. 2002. S6 phosphorylation-independent pathways regulate translation of 5 '-terminal oligopyrimidine tract-containing mRNAs in differentiating hematopoietic cells. Nucleic Acids Res 30: 1919-1928.

Bekinschtein P, Katche C, Slipczuk LN, Igaz LM, Cammarota M, Izquierdo I, Medina JH. 2007. mTOR signaling in the hippocampus is necessary for memory formation. Neurobiol Learn Mem 87: 303-307.

Belelovsky K, Elkobi A, Kaphzan H, Nairn AC, Rosenblum K. 2005. A molecular switch for translational control in taste memory consolidation. Eur J Neurosci 22: 2560-2568.

Biever A, Puighermanal E, Nishi A, David A, Panciatici C, Longueville S, Xirodimas D, Gangarossa G, Meyuhas O, Hervé D, et al. 2015a. PKA-dependent phosphorylation of ribosomal protein S6 does not correlate with translation efficiency in striatonigral and striatopallidal medium-sized spiny neurons. J Neurosci 35: 4113-4130.

Biever A, Valjent E, Puighermanal E. 2015b. Ribosomal protein S6 phosphorylation in the nervous system: from regulation to function. Front Mol Neurosci 8: 75.

Bliss TV, Collingridge GL. 1993. A synaptic model of memory: long-term potentiation in the hippocampus. Nature 361: 31-39.

Bliss TV, Lomo T. 1973. Long-lasting potentiation of synaptic transmission in the dentate area of the anaesthetized rabbit following stimulation of the perforant path. J Physiol (Lond) 232: 331-356.

Bramham CR, Worley PF, Moore MJ, Guzowski JF. 2008. The immediate early gene Arc/Arg3.1: regulation, mechanisms, and function. J Neurosci 28: $11760-11767$.

Burgin KE, Waxham MN, Rickling S, Westgate SA, Mobley WC, Kelly PT. 1990. In situ hybridization histochemistry of Ca2+/ calmodulin-dependent protein kinase in developing rat brain. J Neurosci 10: 1788-1798.

Cajigas IJ, Tushev G, Will TJ, tom Dieck S, Fuerst N, Schuman EM. 2012 The local transcriptome in the synaptic neuropil revealed by deep sequencing and high-resolution imaging. Neuron 74: 453-466.

Cammalleri M, Lutjens R, Berton F, King AR, Simpson C, Francesconi W, Sanna PP. 2003. Time-restricted role for dendritic activation of the mTOR-p70S6K pathway in the induction of late-phase long-term potentiation in the CA1. Proc Natl Acad Sci 100: 14368-14373.

Chotiner JK, Nielson J, Farris S, Lewandowski G, Huang F, Banos K, de Leon R, Steward O. 2010. Assessment of the role of MAP kinase in mediating activity-dependent transcriptional activation of the immediate early gene Arc/Arg3.1 in the dentate gyrus in vivo. Learn Mem 17: 117-129.

Cortes-Mendoza J, Diaz de Leon-Guerrero S, Pedraza-Alva G, Perez-Martinez L. 2013. Shaping synaptic plasticity: the role of activity-mediated epigenetic regulation on gene transcription. Int J Dev Neurosci 31: 359-369.

Dash PK, Orsi SA, Moore AN. 2006. Spatial memory formation and memory-enhancing effect of glucose involves activation of the tuberous sclerosis complex-Mammalian target of rapamycin pathway. J Neurosci 26: 8048-8056.

Davis S, Vanhoutte P, Pagès C, Caboche J, Laroche S. 2000. The MAPK/ERK cascade targets both Elk-1 and cAMP response element-binding protein to control long-term potentiation-dependent gene expression in the dentate gyrus in vivo. J Neurosci 20: $4563-4572$.

Desmond NL, Levy WB. 1983. Synaptic correlates of associative potentiation/depression: an ultrastructural study in the hippocampus. Brain Res 265: 21-30. 
Douglas RM, Goddard GV. 1975. Long-term potentiation of the perforant path-granule cell synapse in the rat hippocampus. Brain Res 86: 205-215.

Duncan R, McConkey EH. 1982. Preferential utilization of phosphorylated 40-S ribosomal subunits during initiation complex formation. Eur $J$ Biochem 123: 535-538.

Farris S, Lewandowski G, Cox CD, Steward O. 2014. Selective localization of arc mRNA in dendrites involves activity- and translation-dependent mRNA degradation. J Neurosci 34: 4481-4493.

Fifková E, Van Harreveld A. 1977. Long-lasting morphological changes in dendritic spines of dentate granular cells following stimulation of the entorhinal area. J Neurocytol 6: 211-230.

Flotow H, Thomas G. 1992. Substrate recognition determinants of the mitogen-activated 70K S6 kinase from rat liver. J Biol Chem 267: 3074-3078.

Fukazawa Y, Saitoh Y, Ozawa F, Ohta Y, Mizuno K, Inokuchi K. 2003. Hippocampal LTP is accompanied by enhanced F-actin content within the dendritic spine that is essential for late LTP maintenance in vivo. Neuron 38: $447-460$.

Gobert D, Topolnik L, Azzi M, Huang L, Badeaux F, Desgroseillers L, Sossin WS, Lacaille JC. 2008. Forskolin induction of late-LTP and up-regulation of $5^{\prime}$ TOP mRNAs translation via mTOR, ERK, and PI3K in hippocampal pyramidal cells. J Neurochem 106: 1160-1174.

Gressner AM, Wool IG. 1974. The phosphorylation of liver ribosomal proteins in vivo. Evidence that only a single small subunit protein (S6) is phosphorylated. J Biol Chem 249: 6917-6925.

Gustafsson B, Wigström H. 1988. Physiological mechanisms underlying long-term potentiation. Trends Neurosci 11: 156-162.

Guzowski JF, McNaughton BL, Barnes CA, Worley PF. 1999. Environment-specific expression of the immediate-early gene Arc in hippocampal neuronal ensembles. Nat Neurosci 2: 1120-1124.

Guzowski JF, Lyford GL, Stevenson GD, Houston FP, McGaugh JL, Worley PF, Barnes CA. 2000. Inhibition of activity-dependent arc protein expression in the rat hippocampus impairs the maintenance of long-term potentiation and the consolidation of long-term memory. J Neurosci 20: 3993-4001.

Harris EW, Ganong AH, Cotman CW. 1984. Long-term potentiation in the hippocampus involves activation of N-methyl-D-aspartate receptors. Brain Res 323: 132-137.

Harris KM, Fiala JC, Ostroff L. 2003. Structural changes at dendritic spine synapses during long-term potentiation. Philos Trans R Soc Lond B Biol Sci 358: $745-748$.

Hess US, Lynch G, Gall CM. 1995. Regional patterns of c-fos mRNA expression in rat hippocampus following exploration of a novel environment versus performance of a well-learned discrimination. J Neurosci 15: 7796-7809.

Hoeffer CA, Klann E. 2010. mTOR signaling: at the crossroads of plasticity, memory and disease. Trends Neurosci 33: 67-75.

Huang F, Chotiner JK, Steward O. 2007. Actin polymerization and ERK phosphorylation are required for Arc/Arg3.1 mRNA targeting to activated synaptic sites on dendrites. J Neurosci 27: 9054-9067.

Impey S, Obrietan K, Wong ST, Poser S, Yano S, Wayman G, Deloulme JC, Chan G, Storm DR. 1998. Cross talk between ERK and PKA is required for $\mathrm{Ca} 2+$ stimulation of CREB-dependent transcription and ERK nuclear translocation. Neuron 21: 869-883.

Jacinto E, Hall MN. 2003. TOR signalling in bugs, brain and brawn. Nat Rev Mol Cell Bio 4: 117-126.

Jefferies HBJ. 1997. Rapamycin suppresses 5'TOP mRNA translation through inhibition of p70s6k. EMBO J 16: 3693-3704.

Jefferies HBJ, Thomas G. 1996. Ribosomal protein S6 phosphorylation and signal transduction. In Translational control (ed. Hershey JW, Mathews MB, Sonenberg N), pp. 389-409. Cold Spring Harbor Laboratory Press, Cold Spring Harbor, NY.

Jefferies HB, Reinhard C, Kozma SC, Thomas G. 1994. Rapamycin selectively represses translation of the "polypyrimidine tract" mRNA family. Proc Natl Acad Sci 91: 4441-4445.

Kandel ER. 2001. The molecular biology of memory storage: a dialogue between genes and synapses. Science 294: 1030-1038.

Kelleher RJ III, Govindarajan A, Tonegawa S. 2004a. Translational regulatory mechanisms in persistent forms of synaptic plasticity. Neuron 44: 59-73.

Kelleher RJ, Govindarajan A, Jung H-Y, Kang H, Tonegawa S. 2004b. Translational control by MAPK signaling in long-term synaptic plasticity and memory. Cell 116: 467-479.

Klann E, Dever TE. 2004. Biochemical mechanisms for translational regulation in synaptic plasticity. Nat Rev Neurosci 5: 931-942.

Krieg J, Hofsteenge J, Thomas G. 1988. Identification of the $40 \mathrm{~S}$ ribosomal protein S6 phosphorylation sites induced by cycloheximide. J Biol Chem 263: 11473-11477.

Kruppa J, Clemens MJ. 1984. Differential kinetics of changes in the state of phosphorylation of ribosomal protein $\mathrm{S} 6$ and in the rate of protein synthesis in MPC 11 cells during tonicity shifts. EMBO J 3: 95-100.
Lenz G, Avruch J. 2005. Glutamatergic regulation of the p70S6 kinase in primary mouse neurons. J Biol Chem 280: 38121-38124.

Levy WB, Steward O. 1979. Synapses as associative memory elements in the hippocampal formation. Brain Res 175: 233-245.

Lin B, Kramar EA, Bi X, Brucher FA, Gall CM, Lynch G. 2005. Theta stimulation polymerizes actin in dendritic spines of hippocampus. $J$ Neurosci 25: 2062-2069.

Link W, Konietzko U, Kauselmann G, Krug M, Schwanke B, Frey U, Kuhl D. 1995. Somatodendritic expression of an immediate early gene is regulated by synaptic activity. Proc Natl Acad Sci 92: 5734-5738.

Lyford GL, Yamagata K, Kaufmann WE, Barnes CA, Sanders LK, Copeland NG, Gilbert DJ, Jenkins NA, Lanahan AA, Worley PF. 1995. Arc, a growth factor and activity-regulated gene, encodes a novel cytoskeleton-associated protein that is enriched in neuronal dendrites. Neuron 14: 433-445.

Lynch G, Baudry M. 1984. The biochemistry of memory: a new and specific hypothesis. Science 224: 1057-1063.

Lynch G, Kramár EA, Gall CM. 2014. Protein synthesis and consolidation of memory-related synaptic changes. Brain Res 1621: 62-72.

Malenka RC, Kauer JA, Perkel DJ, Mauk MD, Kelly PT, Nicoll RA, Waxham MN. 1989. An essential role for postsynaptic calmodulin and protein kinase activity in long-term potentiation. Nature 340: $554-557$.

Medvedev NI, Popov VI, Dallérac G, Davies HA, Laroche S, Kraev IV, Rodriguez Arellano JJ, Doyère V, Stewart MG. 2010. Alterations in synaptic curvature in the dentate gyrus following induction of long-term potentiation, long-term depression, and treatment with the N-methyl-d-aspartate receptor antagonist CPP. Neuroscience 171: 390-397.

Meyuhas O. 2000. Synthesis of the translational apparatus is regulated at the translational level. Eur J Biochem 267: 6321-6330.

Meyuhas O. 2008. Chapter 1 physiological roles of ribosomal protein S6: one of its kind. In International review of cell and molecular biology, Vol. 268, pp. 1-37. Elsevier.

Meyuhas O. 2015. Ribosomal protein S6 phosphorylation: four decades of research. Int Rev Cell Mol Biol 320: 41-73.

Mieulet V, Roceri M, Espeillac C, Sotiropoulos A, Ohanna M, Oorschot V, Klumperman J, Sandri M, Pende M. 2007. S6 kinase inactivation impairs growth and translational target phosphorylation in muscle cells maintaining proper regulation of protein turnover. Am J Physiol Cell Physiol 293: C712-C722.

Moore CE, Xie J, Gomez E, Herbert TP. 2009. Identification of cAMP-dependent kinase as a third in vivo ribosomal protein S6 kinase in pancreatic $\beta$-cells. J Mol Biol 389: 480-494.

Nguyen PV, Kandel ER. 1996. A macromolecular synthesis-dependent late phase of long-term potentiation requiring cAMP in the medial perforant pathway of rat hippocampal slices. J Neurosci 16: 3189-3198.

Nguyen PV, Abel T, Kandel ER. 1994. Requirement of a critical period of transcription for induction of a late phase of LTP. Science 265: $1104-1107$.

Nielsen PJ, Duncan R, McConkey EH. 1981. Phosphorylation of ribosomal protein S6. Relationship to protein synthesis in HeLa cells. Eur J Biochem 120: $523-527$.

Nihonmatsu I, Ohkawa N, Saitoh Y, Inokuchi K. 2015. Targeting of ribosomal protein $\mathrm{S} 6$ to dendritic spines by in vivo high frequency stimulation to induce long-term potentiation in the dentate gyrus. Biol Open 4: 1387-1394.

Nygard O, Nilsson L. 1990. Translational dynamics. Interactions between the translational factors, tRNA and ribosomes during eukaryotic protein synthesis. Eur J Biochem 191: 1-17.

Panja D, Dagyte G, Bidinosti M, Wibrand K, Kristiansen AM, Sonenberg N, Bramham CR. 2009. Novel translational control in Arc-dependent long term potentiation consolidation in vivo. J Biol Chem 284: $31498-31511$

Parsons RG, Gafford GM, Helmstetter FJ. 2006. Translational control via the mammalian target of rapamycin pathway is critical for the formation and stability of long-term fear memory in amygdala neurons. J Neurosci 26: $12977-12983$.

Pende M, Um SH, Mieulet V, Sticker M, Goss VL, Mestan J, Mueller M, Fumagalli S, Kozma SC, Thomas G. 2004. S6 $\mathrm{K}^{-1-} / \mathrm{S} 6 \mathrm{~K}^{-/-}$mice exhibit perinatal lethality and rapamycin-sensitive $5^{\prime}$-terminal oligopyrimidine mRNA translation and reveal a mitogen-activated protein kinase-dependent S6 kinase pathway. Mol Cell Biol 24: $3112-3124$.

Proud CG. 2002. Regulation of mammalian translation factors by nutrients. Eur I Biochem 269: 5338-5349.

Qi S, Mizuno M, Yonezawa K, Nawa H, Takei N. 2010. Activation of mammalian target of rapamycin signaling in spatial learning. Neurosci Res 68: 88-93.

Ramirez-Amaya V, Vazdarjanova A, Mikhael D, Rosi S, Worley PF, Barnes CA. 2005. Spatial exploration-induced Arc mRNA and protein 
expression: evidence for selective, network-specific reactivation. $J$ Neurosci 25: 1761-1768.

Roux PP, Shahbazian D, Vu H, Holz MK, Cohen MS, Taunton J, Sonenberg N, Blenis J. 2007. RAS/ERK signaling promotes site-specific ribosomal protein S6 phosphorylation via RSK and stimulates cap-dependent translation. J Biol Chem 282: 14056-14064.

Ryan MM, Mason-Parker SE, Tate WP, Abraham WC, Williams JM. 2011. Rapidly induced gene networks following induction of long-term potentiation at perforant path synapses in vivo. Hippocampus 21: 541-553.

Smith CJ, Wejksnora PJ, Warner JR, Rubin CS, Rosen OM. 1979. Insulin-stimulated protein phosphorylation in 3T3-L1 preadipocytes. Pro Natl Acad Sci 76: 2725-2729.

Steward O, Levy WB. 1982. Preferential localization of polyribosomes under the base of dendritic spines in granule cells of the dentate gyrus. J Neurosci 2: 284-291.

Steward O, Schuman EM. 2001. Protein synthesis at synaptic sites on dendrites. Аппи Rev Neurosci 24: 299-325.

Steward O, Worley PF. 2001. Selective targeting of newly synthesized Arc mRNA to active synapses requires NMDA receptor activation. Neuron 30: $227-240$.

Steward O, Wallace C, Lyford G, Worley P. 1998. Synaptic activation causes the mRNA for the IEG Arc to localize selectively near activated postsynaptic sites on dendrites. Neuron 21: 741-751.

Stolovich M, Tang H, Hornstein E, Levy G, Cohen R, Bae SS, Birnbaum MJ, Meyuhas O. 2002. Transduction of growth or mitogenic signals into translational activation of TOP mRNAs is fully reliant on the phosphatidylinositol 3-kinase-mediated pathway but requires neither S6K1 nor rpS6 phosphorylation. Mol Cell Biol 22: 8101-8113.

Tang H, Hornstein E, Stolovich M, Levy G, Livingstone M, Templeton D, Avruch J, Meyuhas O. 2001. Amino acid-induced translation of TOP mRNAs is fully dependent on phosphatidylinositol 3-kinase-mediated signaling, is partially inhibited by rapamycin, and is independent of S6K1 and rpS6 phosphorylation. Mol Cell Biol 21: 8671-8683.

Thomas G, Martin-Pérez J, Siegmann M, Otto AM. 1982. The effect of serum, EGF, PGF2 $\alpha$ and insulin on $\$ 6$ phosphorylation and the initiation of protein and DNA synthesis. Cell 30: 235-242.
Tiedge H, Brosius J. 1996. Translational machinery in dendrites of hippocampal neurons in culture. J Neurosci 16: 7171-7181.

Tsokas P. 2005. Local protein synthesis mediates a rapid increase in dendritic elongation factor $1 \mathrm{~A}$ after induction of late long-term potentiation. J Neurosci 25: 5833-5843.

Tsokas P, Ma T, Iyengar R, Landau EM, Blitzer RD. 2007. Mitogen-activated protein kinase upregulates the dendritic translation machinery in long-term potentiation by controlling the mammalian target of rapamycin pathway. J Neurosci 27: 5885-5894.

Vann SD, Brown MW, Erichsen JT, Aggleton JP. 2000. Fos imaging reveals differential patterns of hippocampal and parahippocampal subfield activation in rats in response to different spatial memory tests. J Neurosci 20: 2711-2718.

Vazdarjanova A, Ramirez-Amaya V, Insel N, Plummer TK, Rosi S, Chowdhury S, Mikhael D, Worley PF, Guzowski JF, Barnes CA. 2006. Spatial exploration induces ARC, a plasticity-related immediate-early gene, only in calcium/calmodulin-dependent protein kinase II-positive principal excitatory and inhibitory neurons of the rat forebrain. J Comp Neurol 498: 317-329.

Wallace CS, Lyford GL, Worley PF, Steward O. 1998. Differential intracellular sorting of immediate early gene mRNAs depends on signals in the mRNA sequence. J Neurosci 18: 26-35.

Wettenhall RE, Erikson E, Maller JL. 1992. Ordered multisite phosphorylation of Xenopus ribosomal protein S6 by S6 kinase II. J Biol Chem 267: 9021-9027.

Wigström H, Gustafsson B. 1986. Postsynaptic control of hippocampal long-term potentiation. J Physiol (Paris) 81: 228-236.

Worley PF, Christy BA, Nakabeppu Y, Bhat RV, Cole AJ, Baraban JM. 1991. Constitutive expression of zif268 in neocortex is regulated by synaptic activity. Proc Natl Acad Sci 88: 5106-5110.

Received February 22, 2016; accepted in revised form March 7, 2016. 


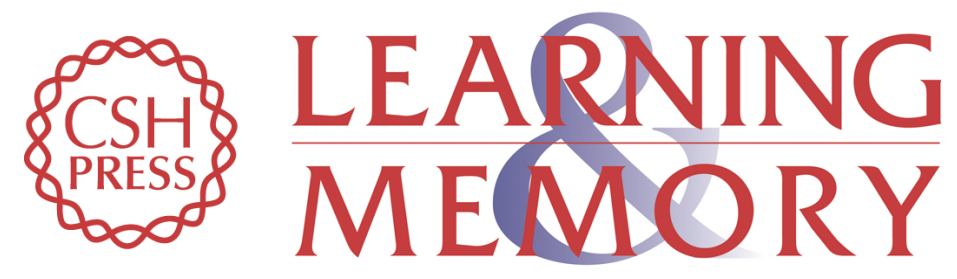

\section{Synaptic activation of ribosomal protein $\mathbf{S 6}$ phosphorylation occurs locally in activated dendritic domains}

Patricia Salgado Pirbhoy, Shannon Farris and Oswald Steward

Learn. Mem. 2016, 23:

Access the most recent version at doi:10.1101/Im.041947.116

\begin{aligned} & \hline References $\begin{array}{l}\text { This article cites } 90 \text { articles, } 43 \text { of which can be accessed free at: } \\ \text { http://learnmem.cshlp.org/content/23/6/255.full.html\#ref-list-1 }\end{array} \\ & \begin{array}{r}\text { Creative } \\ \text { Commons } \\ \text { License }\end{array} \begin{array}{l}\text { This article is distributed exclusively by Cold Spring Harbor Laboratory Press for the } \\ \text { first } 12 \text { months after the full-issue publication date (see } \\ \text { http://learnmem.cshlp.org/site/misc/terms.xhtml). After } 12 \text { months, it is available under } \\ \text { a Creative Commons License (Attribution-NonCommercial } 4.0 \text { International), as } \\ \text { described at http://creativecommons.org/licenses/by-nc/4.0/. }\end{array} \\ & \begin{array}{c}\text { Receive free email alerts when new articles cite this article - sign up in the box at the } \\ \text { top right corner of the article or click here. }\end{array} \\ & \begin{array}{l}\text { Service } \\ \text { terting }\end{array}\end{aligned}$ 